\title{
MicroRNA-196a-5p is a potential prognostic marker of delayed lymph node metastasis in early-stage tongue squamous cell carcinoma
}

\author{
TESSHO MARUYAMA ${ }^{1,2}$, KAZUHIDE NISHIHARA ${ }^{1,2}$, MASATO UMIKAWA $^{3}$, \\ AKIRA ARASAKI $^{1,2}$, TOSHIYUKI NAKASONE $^{2}$, FUMIKAZU NIMURA $^{1}$, AKIRA MATAYOSHI $^{2}$, \\ KIMIKO TAKEI $^{3}$, SAORI NAKACHI ${ }^{4,5}$, KEN-ICHI KARIYA $^{3}$ and NAOKI YOSHIMI ${ }^{4,5}$ \\ ${ }^{1}$ Department of Oral and Maxillofacial Functional Rehabilitation, Graduate School of Medicine, \\ University of the Ryukyus; ${ }^{2}$ Department of Oral and Maxillofacial Surgery, University Hospital of the Ryukyus; \\ ${ }^{3}$ Department of Medical Biochemistry, Graduate School of Medicine, University of the Ryukyus; \\ ${ }^{4}$ Department of Pathology, University Hospital of the Ryukyus; ${ }^{5}$ Department of Pathology and Oncology, \\ Graduate School of Medicine, University of the Ryukyus, Nishihara, Okinawa 903-0215, Japan
}

Received June 23, 2017; Accepted November 20, 2017

DOI: $10.3892 / \mathrm{ol} .2017 .7562$

\begin{abstract}
MicroRNAs (miRs) are expected to serve as prognostic tools for cancer. However, many miRs have been reported as prognostic markers of recurrence or metastasis in oral squamous cell carcinoma patients. We aimed to determine the prognostic markers in early-stage tongue squamous cell carcinoma (TSCC). Based on previous studies, we hypothesized that miR-10a, 10b, 196a-5p, 196a-3p, and 196b were prognostic markers and we retrospectively performed miR expression analyses using formalin-fixed paraffin-embedded sections of surgical specimens. Total RNA was isolated from cancer tissues and adjacent normal tissue as control, and samples were collected by laser-capture microdissection.
\end{abstract}

Correspondence to: Professor Akira Arasaki, Department of Oral and Maxillofacial Functional Rehabilitation, Graduate School of Medicine, University of The Ryukyus, 207 Uehara, Nishihara, Okinawa 903-0215, Japan

E-mail: arasaki@med.u-ryukyu.ac.jp

Abbreviations: miR, microRNA; TSCC, tongue squamous cell carcinoma; Cq, quantification cycle; LNM, lymph node metastasis; $\mathrm{H} \& \mathrm{~N}$, head and neck; OSCC, oral squamous cell carcinoma; FFPE, formalin-fixed paraffin-embedded; HOX, homeobox; RT-qPCR, reverse transcription-quantitative polymerase chain reaction; ANT, adjacent normal tissue; OS, overall survival; LRFS, local recurrence-free survival; LNMFS, lymph node metastasis-free survival; DMFS, distant metastasis-free survival; DFS, disease-free survival; LMD, laser-capture microdissection; RT, reverse transcription; ROC, receiver operating characteristic; AUC, area under the curve; END, elective neck dissection; mRNA, messenger RNA

Key words: microRNA, tongue, oral cavity, squamous cell carcinoma, miR-196a, lymph node metastasis, regional recurrence, prognostic marker
After cDNA synthesis, reverse transcription-quantitative polymerase chain reaction was performed. Statistical analyses for patient clinicopathological characteristics, recurrence/metastasis, and survival rates were performed to discern their relationships with $\mathrm{miR}$ expression levels, and the $2^{-\Delta \Delta \mathrm{Cq}}$ method was used. miR-196a-5p levels were significantly upregulated in early-stage TSCC, particularly in the lymph node metastasis (LNM) group. The LNM-free survival rate in the low miR-196a-5p $\Delta \Delta \mathrm{Cq}$ value regulation group was found to be lower than that in the high $\Delta \Delta \mathrm{Cq}$ value regulation group $(\mathrm{P}=0.0079)$. Receiver operating characteristic analysis of $\Delta \Delta \mathrm{Cq}$ values revealed that miR-196a-5p had a P-value $=0.0025$, area under the curve $=0.740$, and a cut-off value $=-0.875$ for distinguishing LNM. To our knowledge, this is the first study to examine LNM-related miRs in early-stage TSCC as well as miRs and 'delayed LNM' in head and neck cancer. miR-196a-5p upregulation may predict delayed LNM. Our data serve as a foundation for future studies to evaluate miR levels and facilitate the prediction of delayed LNM during early-stage TSCC, which prevent metastasis when combined with close follow-up and aggressive adjuvant therapy or elective neck dissection. Moreover, our data will serve as a foundation for future studies to evaluate whether miR-196a-5p can serve as a therapeutic marker for preventing metastasis.

\section{Introduction}

Recently, oral cavity cancer, including that of the lip, was found to be the fifteenth most common type of malignancy across populations worldwide, and the site incidence rate of oral cancer was $30.5 \%$ of all head and neck $(\mathrm{H} \& \mathrm{~N})$ regions (including the thyroid gland) $(1,2)$, with an incidence of 275,000 cases annually (3). In the 'Cancer Statistics, 2016,' 31,910 new cases of oral cancer and 6,490 deaths were estimated in the U.S. (4), and both of these values are 1.5 -fold higher than the values in the past two decades $(5,6)$. Oral squamous cell carcinoma (OSCC) represents a majority of 
oral cancer cases, and the major site of occurrence is the tongue $(7,8)$. Among the OSCC cases, the rate of early-stage OSCC has increased gradually, and, to date, $67.4-80 \%$ of all OSCCs have been reported to be early-stage OSCCs $(9,10)$. Therefore, early-stage tongue squamous cell carcinoma (TSCC) is one of the most common H\&N cancers $(1,7,9,10)$. The standard treatment of early-stage OSCC, including TSCC remains surgery, with the addition of adjuvant therapy for advanced features such as positive surgical margins and detection of venous, lymphatic, or neural invasion (11), which has remained relatively unchanged to date (9). Local recurrence and lymph node metastasis (LNM) are the main causes of death in patients with early-stage oral cancer $(12,13)$ because the relapse is generally followed by distant metastasis (14). The survival rate of the tumor depends on local recurrence, LNM, and distant metastasis (12). A relatively higher rate of neck LNM has been reported in OSCC (4). In particular, TSCC is well known to be associated with an increased tendency for LNM (15). Early stage cancer has basically good prognosis, however, the stages of OSCC have relatively poor prognoses (approximately $40 \%$ of patients died within 3 years) (9), and the primary reason is delayed LNM $(16,17)$. Delayed LNM is generally considered LNM that occurs after primary treatment for cancer (neck dissection was not performed during treatment) $(18,19)$. The prediction of delayed LNM is important in the treatment of early-stage oral cancer (20). Numerous prognostic factors (clinical, pathological, and molecular features) of LNM have been reported to date (2,9,20-24); however, this collectively makes daily clinical practice complex.

MicroRNAs (miRs) are expected to serve as simple markers for prognosis in cancer patients $(25,26)$. Their expressions can be easily detected in not only in fresh tissue but also blood, saliva, and formalin-fixed paraffin-embedded (FFPE) tissues (27-30). They are small (19-25 nt in length), non-coding RNAs known to critically regulate various oncogenes or tumor suppressor gene expressions (31-35). To date, more than 2,600 human miRs are present in the miRbase (Release 21), a database that stores miR data, and $60 \%$ of human protein-coding genes have been reported to be regulated by miRs (36). miRs play important roles in the regulation of OSCC and may serve as prognostic factors (15,37-40). To date, many studies have investigated miR regulation in oral cancer. As a result, a plethora of miRs have been identified as prognostic factors for recurrence or metastasis in OSCC patients. There are also many pathways of cancer progression or metastasis that relate to miRs are present (41). Additionally, various kinds of oral cancer-related genes and pathways are present and these might be associated with tumor recurrence and metastasis (3,7,25,34,41-43). Among the miRs, miR-10a, miR-10b, miR-196a, miR-196b, and miR-615, which reside in Homeobox (HOX) gene clusters, have been the focus of much attention recently $(25,44-46)$. Increased regulation of $H O X$ genes is associated with the proliferation and migration of OSCC cells, which can lead to recurrence or metastasis in OSCC patients (45). Among the five miRs, miR-615 from examination has the sparsity of studies (47). The remaining four miRs (miR-10a, miR-10b, miR-196a, and miR-196b) have been shown to be related to various target genes and to control many types of malignancies or other diseases $(34,48-51)$. In particular, some genes regulated by
miR-196, impact recurrence or metastasis $(34,45,46,52,53)$. Thus, miR-196 expression and functional have been investigated $(29,46,52,54)$. Those four miRs (miR-10a, miR-10b, miR-196a, and miR-196b) have been shown to be related with OSCC in the previous studies $(29,52,55,56)$. Therefore, we selected miRs as candidates in this study.

For OSCC patients, it is critically more important to identify prognostic rather than diagnostic markers. Among all malignancies, OSCC is relatively easy to detect because the oral cavity can be directly observed. However, to date, no approaches can monitor recurrence and metastasis in early-stage TSCC (39). Furthermore, no useful miR marker can predict recurrence or metastasis, particularly delayed LNM in patients with early-stage OSCC. Some studies have reported several miRs as prognostic markers of local recurrence or LNM; however, their data were relevant to 'all stages' and not only to the early stages of the disease $(57,58)$. Among our candidate miRs, miR-196a reportedly serves as a useful prognostic marker of 'locoregional recurrence' (local recurrence and/or regional LNM) in OSCC $(29,45,52)$, although the cited studies focused on 'all stages' of OSCC throughout the oral cavity and did not distinguish between local recurrence and LNM. To examine local recurrence or delayed LNM, only LNM after treatment should be investigated. Moreover, there are few studies on miR expression in early-stage OSCC $(10,59,60)$. We hypothesized that the above-mentioned miRs could be useful prognostic markers of early-stage TSCC. For testing this hypothesis, we used reverse transcription-quantitative polymerase chain reaction (RT-qPCR) to analyze the expression of the miRs in FFPE tissues of patients with early-stage TSCC compared the findings with those of adjacent normal tissue (ANT) in order to determine the relationship between miR expressions and disease features.

\section{Materials and methods}

Patients and tissue samples. Informed consent was obtained from all patients. The Ethics Committee of the University of the Ryukyus (Okinawa, Japan) approved this study on June 22, 2016 (approval no. 957), and the study complied with the Declaration of Helsinki. The Conflict of Interest Committee of the University of the Ryukyus approved this study on June 22, 2016, and the authors have no conflicts of interest to disclose. Samples of cancer tissue and ANT were retrospectively collected from 50 patients with primary early-stage TSCC (cT1T2N0) clinically (excluding cancer in situ, dysplasia, pre-cancer diseases, and verrucous carcinoma), who were aged $\geq 20$ years and diagnosed by our department. All patients underwent surgical excision between January 2005 and December 2014. All cancers were located on the mobile tongue. Some cases were from our previous retrospective study (61), whose aim was to compare patients who underwent surgery alone to those with neoadjuvant chemotherapy and surgery. The current study excluded patients who underwent neoadjuvant therapy. Therefore, no methods or results from the previous study were included in the current study.

No LNM or distant metastasis was confirmed by assessing clinical symptoms and radiological lesions before surgery. All alive patients were followed for $\geq 2$ years after treatment, which is considered an appropriate timeframe to evaluate recurrence 
or metastases $(17,62)$. The maximum length of follow-up was 5 years (63). We excluded the following patients: i) who received chemotherapy, radiotherapy, or both before surgery; ii) who underwent simultaneous neck dissections (in all patients, no LNM was suspected clinically or radiologically; therefore, LNM after curative surgery could be defined as 'delayed' LNM); iii) two or more additional resections on the day after the first local resection because of positive margins; iv) who had coexisting cancer; and v) patients with a history of $H \& N$ cancers or those who underwent treatment for these tumors.

The surgical margins used were $\geq 10 \mathrm{~mm}$ clinically for all patients; thus, the resection margins of all tumors were microscopically free of cancer cells. In three cases with closed surgical margins, tumors were pathologically found a few days after surgery, and adjuvant chemotherapy (oral therapy of S-1) was administered. No patient received adjuvant radiotherapy. All stained tissues were reviewed by pathologists at the Department of Pathology, University Hospital of the Ryukyus. Histological grades were classified by pathologists according to the WHO guidelines (64) as well, moderate, or poor. There was no undifferentiated type. The mode of invasion was divided into four main grades $(1,2,3$, and $4 \mathrm{C} / 4 \mathrm{D})$ by using the criteria proposed by Yamamoto et al. for hematoxylin and eosin specimens (65). Lymphatic, venous, and neural invasions were evaluated with immunohistochemical stains or special stains, including D2-40 (code M3619; Dako, Glostrup, Denmark), Victoria blue (no. 4077; Muto Pure Chemical Co., Ltd., Tokyo, Japan), and S-100 (cat. no. Z0311; Dako), respectively. Tumor depth was measured vertically between the adjacent normal mucosa surface and the deepest point of tumor invasion (66). All stained slides were 3- $\mu \mathrm{m}$ thick and were obtained from surgical specimens. Patient history of alcohol use or smoking was determined. No patient chewed betel quid, which is a high-risk factor for oral cancer. The definitions of recurrence/metastasis were as follows: i) local recurrence: lesions appearing in the oral cavity and nearly where resection for tongue cancer was performed between 6 weeks and 5 years after the first curative surgery; ii) LNM: lesions appearing only in the neck lymph node region between 6 weeks and 5 years after the first curative surgery; and iii) distant metastasis: distant lesions appearing between 6 weeks and 5 years after the first curative surgery (63). In the present study, no combination of local recurrence or LNM was found. At the time of diagnosis, distant metastases, local recurrence, or LNM was not found. Overall survival (OS) was defined as the time from the date of surgical excision to the date of death or last follow-up. Local recurrence-free survival (LRFS), LNM-free survival (LNMFS), distant metastasis-free survival (DMFS), and disease-free survival (DFS) were defined as the time from the date of surgical excision to the date of local recurrence, LNM, distant metastasis, and any recurrence or metastasis, respectively, or the last follow-up day, including death without recurrence.

Collection of target samples from FFPE tissues using laser-capture microdissection (LMD). FFPE tissues acquired from surgical excisions or biopsies were collected for analysis. Before performing LMD, pathologists classified the cancer and ANT areas. ANTs were defined as epithelial tissues located on the surgical margin that were $\geq 5 \mathrm{~mm}$ away from cancer tissues. A microtome (Leica RM2235; Leica Biosystems Nussloch GmbH, Nussloch, Germany) was used to prepare $7-\mu \mathrm{m}$-thick tissue sections from FFPE tissue blocks, which were placed on nuclease-free 1.0 PEN Membrane Slides (no. 415190-9081-000; Zeiss GmbH, Jena, Germany). Then, tissue sections were deparaffinized, stained with cresyl violet, and dried in air briefly, and the slides were subsequently stored at $-20^{\circ} \mathrm{C}$. LMD was performed using a Zeiss PALM Microbeam laser microdissection system (Carl Zeiss Microscopy, Jena, Germany) and PALM Robo v4.6 software. For capturing tissue, Adhesive Caps (no. 415190-9201-000; Zeiss GmbH) were used. Tissue sections (cancer tissue and paired ANT) were immediately deparaffinized and total RNA was then extracted.

$R T-q P C R$. Total RNA was extracted from FFPE tissues using an miRNeasy FFPE kit (Qiagen GmbH, Hilden, Germany) (67), which involved removal of genomic DNA contamination and RNA purification with RNeasy MinElute. The sample was stored at $-80^{\circ} \mathrm{C}$ before use for reverse transcription (RT). The purity of total RNA was examined using BioSpec-nano (Shimadzu, Kyoto, Japan). RT was performed using a Taqman microRNA RT kit (Thermo Fisher Scientific, Inc., Waltham, MA, USA) (68) with $5 \mu$ l of total RNA, and cDNA samples were stored at $-20^{\circ} \mathrm{C}$ before use. We selected miR-196a-3p to evaluate miR-196a-2. TaqMan miRNA assays (Thermo Fisher Scientific, Waltham, Inc.) were used to assess the relative expressions of the following five miRs: miR-10a (miR-10a-5p: assay ID 000387, mature miR sequence: UAC CCUGUAGAUCCGAAUUUGUG), miR-10b (miR-10b-5p: assay ID 002218, mature miR sequence: UACCCUGUAGAA CCGAAUUUGUG), miR-196a-5p (assay ID 241070_mat, mature miR sequence: UAGGUAGUUUCAUGUUGUUGG G), miR-196a-3p (assay ID 002336, mature miR sequence: CGGCAACAAGAAACUGCCUGAG), and miR-196b (miR196b-5p: assay ID 002215, mature miR sequence: UAGGUA GUUUCCUGUUGUUGGG), according to the manufacturer's instructions. The reactions were carried out at $50{ }^{\circ} \mathrm{C}$ for $2 \mathrm{~min}$ and at $95^{\circ} \mathrm{C}$ for $10 \mathrm{~min}$, followed by 40 cycles at $95^{\circ} \mathrm{C}$ for $15 \mathrm{sec}$ and at $60^{\circ} \mathrm{C}$ for $60 \mathrm{sec}$. All experiments were carried out in triplicate. Data were analyzed with the $2^{-\Delta \Delta \mathrm{Cq}}$ method (69). Data were normalized using small nuclear RNAs 44 and 48 (RNU44, assay ID 001094; RNU48, assay ID 001006; Thermo Fisher Scientific, Inc.) as endogenous controls. In all 50 patients, RNU44 and 48 could be determined. The undetermined $\mathrm{Cq}$ value of the other five miRs (miR-10a, miR-10b, miR-196a-5p, miR-196a-3p, and miR-196b) was estimated as $40 \mathrm{Cq}(70,71)$. The formulas were as follows: $\Delta \mathrm{Cq}$ (cancer) value $=(\mathrm{Cq}$ value of cancer tissue $)$ - $($ the average $\mathrm{Cq}$ value of RNU44 and RNU48); $\Delta \mathrm{Cq}$ (normal) value $=(\mathrm{Cq}$ value of normal tissue)-(the average $\mathrm{Cq}$ value of RNU44 and RNU48); and $\Delta \Delta \mathrm{Cq}$ value $=\Delta \mathrm{Cq}$ (cancer) value $-\Delta \mathrm{Cq}$ (normal) value. A lower $\Delta \mathrm{Cq}$ value represented higher expression of miR. A lower $\Delta \Delta \mathrm{Cq}$ value represented higher expression of $\mathrm{miR}$ in cancer tissues than in paired ANTs of the same patient.

Statistical analysis. The Gaussian distribution of each group was tested using Shapiro-Wilk test. The homogeneity of variances was confirmed using the Levene test. For data with a Gaussian distribution, the difference between two groups 
was demonstrated using the Student's t-test or the Welch's t-test, depending on the homogeneity of the variances. For data that did not conform to a Gaussian distribution, the Mann-Whitney U test was applied. When analyzing three or more subgroups, one-way ANOVA or the Kruskal-Wallis test was used to assess whether the data conformed to a Gaussian distribution. The association of the $\Delta \mathrm{Cq}$ value between early-stage TSCC tissue and paired ANT was confirmed using a paired t-test. The $\Delta \Delta \mathrm{Cq}$ values and the clinicopathological characteristics of the patients were evaluated using the tests mentioned above. Differences in the patient numbers between high and low $\Delta \Delta \mathrm{Cq}$ value regulation groups were evaluated using a two-tailed Fisher's exact test. Survival analyses (OS, LRFS, LNMFS, DMFS, and DFS) were performed using the Kaplan-Meier method, and survival curves were compared using the log-rank test. A receiver operating characteristic (ROC) curve analysis was performed and area under the ROC curve (AUC) was determined to examine the feasibility of using the $\Delta \Delta \mathrm{Cq}$ value as an approach for assessing the prognosis of delayed LNM and the mode of tumor invasion. Youden index was calculated for the identification of the best $\Delta \Delta$ Cq cut-off value. $\mathrm{P}<0.05$ was considered to indicate statistical significance. All statistical analyses were performed using JMP software (JMP Version Pro 12; SAS Institute Inc., Cary, NC, USA).

\section{Results}

Characteristics. Table I presents the characteristics of the patients. The numbers of patients with local recurrence, delayed LNM, and distant metastasis were 4, 17, and 3, respectively. All distant metastases occurred after treatment and control of delayed LNM. The clinical T stage was cT1 in 32 patients and cT2 in 18 patients. The histological grade was $\mathrm{G} 1 /$ well in 31 patients, G2/moderate in 16 patients, and G3/poor in 1 patient. The mode of tumor invasion was 1-3 in 39 patients and 4C-4D in 11 patients. The depth of the tumor was $<5 \mathrm{~mm}$ in 42 patient and between 5 and $10 \mathrm{~mm}$ in eight patients. Lymphatic, venous, and neural invasions were found in six, five, and five patients, respectively. Nineteen patients were current or past smokers and 22 were current or past alcohol drinkers.

All 5 miRs were significantly expressed in early-stage TSCC tissues. The levels of all five candidate miRs showed significant differences between early-stage TSCC tissues and ANTs, and P-values for miR-196a-5p, miR-196b, miR-10a, miR-10b, and miR-196a-3p were $<0.001,<0.001,<0.001,<0.001$, and 0.003 , respectively (Fig. 1A-E). miR-196a-5p and miR-196b were upregulated (Fig. 1A and B) while miR-196a-3p, miR-10a, and miR-10b were downregulated in early-stage TSCC tumors (Fig. 1C-E). Thus, all five miRs were viable biomarkers.

Clinicopathological significance of $m i R$ levels in early-stage TSCC. We analyzed the association between miR expression (using $\Delta \Delta \mathrm{Cq}$ values) and clinicopathological parameters (Table II). For several characteristics, the P-values were significant. The $\Delta \Delta \mathrm{Cq}$ values of miR-196a-5p and miR-196a-3p were significantly different between the local recurrence and no recurrence groups. The $\Delta \Delta \mathrm{Cq}$ values of miR-196a-5p and
miR-196a-3p were also significantly different between the delayed LNM and no LNM groups. In the distant metastasis subgroup, the $\Delta \Delta \mathrm{Cq}$ values of miR-196b were significantly different. Furthermore, in the sex, clinical stage, mode of tumor invasion, depth of tumor, and smoking subgroups, the $\Delta \Delta \mathrm{Cq}$ values of miR-10b, miR-196b, miR-196a-5p, miR-196a-3p, and miR-10b, respectively, were significantly different. In contrast, there was no significant relationship between miRs levels and age, alcohol intake, and other pathological features such as histological grade, venous/lymphatic invasion, or neural infiltration (Table II). We assessed the most appropriate biomarker candidates. As described above, miR-196a-5p and miR-196b were upregulated (Fig. 1A and B) while miR-196a-3p, miR-10a, and miR-10b were downregulated in early-stage TSCC tissues than in ANTs (Fig. 1C-E). We thought that miR-196a-5p (local recurrence), miR-196a-3p (LNM), miR-196b (distant metastasis), and miR-10b (smoking) were not appropriate markers because some combinations of the subgroups and $\Delta \Delta \mathrm{Cq}$ values were controversial. Further, miR-10b (gender) and miR-196b (clinical, stage) were not appropriate markers because these can be confirmed clinically. On the other hand, we thought that miR-196a-5p (LNM and mode of tumor invasion) and miR-196a-3p (local recurrence) were appropriate candidates because the expressions were consistent.

Association between miR-196a-5p levels and LNMFS in patients with early-stage TSCC. We divided patients using the median $\Delta \Delta \mathrm{Cq}$ value as the cut-off value. On comparing the low miR-196a-5p $\Delta \Delta \mathrm{Cq}$ value regulation (i.e., high expression of miR-196a-5p) group and the high regulation group, no bias was found except with regard to delayed LNM (Table III). Thus, miR-196a-5p could be a prognostic marker. In contrast, on comparing the low miR-196a-3p $\Delta \Delta \mathrm{Cq}$ value regulation (i.e., high expression of miR-196a-3p) group and the high regulation group, bias was found for delayed LNM and depth of tumor (data not shown). Thus, miR-196a-3p could not be considered as a prognostic marker of 'local recurrence' because of the biases. The Kaplan-Meier analysis of each survival curve [OS, LRFS, LNMFS, DMFS, and DFS (Fig. 2A-E, respectively)] indicated that LNMFS was shorter in the low miR-196a-5p $\Delta \Delta \mathrm{Cq}$ value regulation (i.e., higher regulation in TSCC tissues than in ANTs) group than in the high regulation group $(\mathrm{P}=0.0079)$ (Fig. 2C). In contrast, OS, LRFS, DMFS, and DFS showed no significant differences $(\mathrm{P}=0.6205,0.0502,0.5382$, and 0.1049, respectively) (Fig. 2A, B, D and E). In subsequent ROC analysis, $\Delta \Delta \mathrm{Cq}$ values revealed that miR-196a-5p levels yielded $\mathrm{P}=0.0025$, an AUC of 0.740 and a cut-off value of -0.875 to distinguish delayed LNM (Fig. 3A). According to the result presented in Table II, the mode of tumor invasion was also evaluated by ROC analysis. $\Delta \Delta \mathrm{Cq}$ values revealed that miR-196a-5p levels yielded $\mathrm{P}=0.0133$, an AUC of 0.718 and a cut-off value of -0.74 to distinguish $\mathrm{YK}$ grade $4 \mathrm{C}-4 \mathrm{D}$ from $\mathrm{YK}$ grade 1-3 (Fig. 3B).

\section{Discussion}

Our study illustrates two important clinical issues. First, to the best of our knowledge, this is the first study to examine LNM-related miR in early-stage TSCC and is the first miR study of delayed LNM of H\&N cancer. Second, miR-196a-5p 
Table I. Clinicopathological characteristics of our patients $(\mathrm{n}=50)$.

\begin{tabular}{ll}
\hline Subgroups & $\mathrm{n}(\%)$ \\
\hline
\end{tabular}

\section{Age}

$<60$

$21(42)$

$\geq 60$

$29(58)$

Sex

Male

Female

Clinical T stage

I

II

$32(64)$

$18(36)$

Local recurrence

Yes

No

Delayed LNM

Yes

17 (34)

No

Distant metastasis

Yes

No

Histological grade

G1/well

G2/moderate

G3/poor

G4/undifferentiated

Unknown

31 (62)

16 (32)

0 (0)

Mode of tumor invasion

1-3

4C-4D

Depth of tumor

$<5 \mathrm{~mm}$

$5 \mathrm{~mm} \leq$ and $<10 \mathrm{~mm}$

$\geq 10 \mathrm{~mm}$

Lymphatic invation

Yes

No

Unknown

Venous invasion

Yes

No

Neural infiltration

Yes

No

Unknown

Smoking

Current or past

Never

Alcohol intake

Current or past

Never
Table I. Continued.

\begin{tabular}{lc}
\hline Subgroups & $\mathrm{n}(\%)$ \\
\hline Unknown & $3(6)$
\end{tabular}

n, number of cases; LNM, lymph node metastasis.

was significantly upregulated in early-stage TSCC. In addition, miR-196a-5p upregulation increased the risk of delayed LNM and was associated with a shorter LNMFS rate in early-stage TSCC.

We searched the literature from 1993 (72) to 2017 using PubMed and Google Scholar; however, no reports on LNM-related miRs in early-stage TSCC or miR studies on delayed LNM of H\&N cancer were found. Identification of a useful prognostic marker of LNM is an urgent issue in cancer patients who are not only in the advanced stage but also in the early stage.

We focused on delayed LNM for three reasons. First, in general, early-stage OSCC patients have relatively good prognosis when compared to that in advanced-stage patients (73). Fundamentally, early-stage tongue cancer is less likely to result in the distant metastasis (14), which is consistent with our finding; however, delayed LNM worsens the prognosis (16) because LNM is generally followed by distant metastasis (14), which is similar to the findings in our cases. In our study, all distant metastasis cases occurred after delayed LNM. Second, the treatment of early-stage OSCC is still controversial with regard to whether elective neck dissections (ENDs) can be performed $(11,74,75)$, even after a report by D'cruz et al (76) that described the importance of ENDs in early-stage OSCC to improve the survival rate. However, the current guideline of The National Comprehensive Cancer Network (11) does not strongly define END as the standard therapy for early-stage oral cancer. Finally, to evaluate the treatment results without performing END, it is important to clearly distinguish 'delayed' LNM from 'simultaneous' LNM (20).

miR can be reliable markers in daily cancer treatment. Many markers of cancer recurrence or metastasis have been reported (including those described in the new guidelines of the Union for International Cancer Control (2)) and are in use currently. This tends to make the clinician rather uncertain because the markers are too many to use in daily practice. In a recent review, $\mathrm{Yu}$ et al reported that no current clinical or pathological tools that are useful for monitoring recurrence or metastasis in early-stage OSCC patients (39). On the other hand, Irani recently suggested that 'the mode of tumor invasion' is important as a prognostic factor for LNM (77). Based on our results (Table I), we conclude that pathological properties such as mode of tumor invasion, depth of tumor, venous/lymphatic invasion, and neural infiltration can be rarely observed in such early-stage cases $(16,78)$. Additionally, a relatively high rate of well-differentiated tumors was found among our patients, which is not rare and is consistent with a previous finding in a study by Yanamoto et al (63). Only 'the mode of tumor invasion' appeared to be a prognostic factor 25 (50) of delayed LNM according to our results (Table III, Fig. 3B). 
Table II. Association of miR levels and clinicopathological characteristics of our patients $(\mathrm{n}=50)$.

\begin{tabular}{|c|c|c|c|c|c|}
\hline Subgroup & miR-10a & miR-10b & miR-196a-5p & miR-196a-3p & miR-196b \\
\hline \multicolumn{6}{|l|}{ Age } \\
\hline$<60$ & $1.420 \pm 1.330$ & $0.542(-2.02-3.695)$ & $-2.027 \pm 1.819$ & $0.445 \pm 2.144$ & $-2.091 \pm 1.744$ \\
\hline$\geq 60$ & $1.21 \pm 0.993$ & $0.985(-2.135-2.245)$ & $-1.845 \pm 1.999$ & $1.512 \pm 2.541$ & $-1.696 \pm 2.149$ \\
\hline P-value & 0.5250 & 0.1628 & 0.7423 & 0.1247 & 0.4921 \\
\hline \multicolumn{6}{|l|}{ Gender } \\
\hline Male & $1.181 \pm 1.303$ & $0.345 \pm 1.253$ & $-2.101 \pm 2.043$ & $1.128 \pm 2.545$ & $-2.102 \pm 1.628$ \\
\hline Female & $1.406 \pm 0.976$ & $1.058 \pm 1.146$ & $-1.756 \pm 1.799$ & $1.005 \pm 2.345$ & $-1.640 \pm 2.267$ \\
\hline P-value & 0.4904 & 0.0410 & 0.5288 & 0.8603 & 0.4665 \\
\hline \multicolumn{6}{|l|}{ Clinical stage } \\
\hline I & $1.301 \pm 1.245$ & $0.678 \pm 1.255$ & $-1.714 \pm 1.690$ & $1.032 \pm 2.603$ & $-1.443 \pm 1.647$ \\
\hline II & $1.292 \pm 0.955$ & $0.784 \pm 1.246$ & $-2.290 \pm 2.249$ & $1.121 \pm 2.121$ & $-2.606 \pm 2.331$ \\
\hline P-value & 0.9793 & 0.7737 & 0.3112 & 0.9017 & 0.0451 \\
\hline \multicolumn{6}{|l|}{ Local recurrence } \\
\hline Yes & $0.813 \pm 0.760$ & $0.711 \pm 1.092$ & $0.265 \pm 0.554$ & $3.783 \pm 3.902$ & $-0.271 \pm 1.147$ \\
\hline No & $1.340 \pm 1.162$ & $0.716 \pm 1.263$ & $-2.112 \pm 1.866$ & $0.828 \pm 2.154$ & $-2.000 \pm 1.984$ \\
\hline P-value & 0.3805 & 0.9931 & $\mathbf{0 . 0 1 5 3}$ & 0.0175 & 0.0942 \\
\hline \multicolumn{6}{|l|}{ Delayed LNM } \\
\hline Yes & $1.199 \pm 1.164$ & $0.545 \pm 1.514$ & $-2.995 \pm 1.452$ & $0.011 \pm 1.668$ & $-2.224 \pm 1.979$ \\
\hline No & $1.349 \pm 1.140$ & $0.804 \pm 1.088$ & $-1.369 \pm 1.896$ & $1.606 \pm 2.583$ & $-1.666 \pm 1.982$ \\
\hline P-value & 0.6636 & 0.4897 & $\mathbf{0 . 0 0 3 3}$ & 0.0114 & 0.3349 \\
\hline \multicolumn{6}{|l|}{ Distant metastasis } \\
\hline Yes & $2.065(-0.677-2.69)$ & $0.905 \pm 0.587$ & $-2.254 \pm 0.287$ & $0.882 \pm 1.055$ & $-0.645 \pm 0.420$ \\
\hline No & $1.165(-0.655-4.58)$ & $0.704 \pm 1.273$ & $-1.900 \pm 1.967$ & $1.076 \pm 2.486$ & $-1.939 \pm 2.016$ \\
\hline P-value & 0.7131 & 0.7882 & 0.2976 & 0.8946 & 0.0059 \\
\hline \multicolumn{6}{|l|}{ Histological grade } \\
\hline G1/well & $1.178 \pm 1.190$ & $0.642 \pm 1.063$ & $-1.529 \pm 1.854$ & $1.359 \pm 2.821$ & $-0.96(-7.03-2.27)$ \\
\hline $\mathrm{G} 2 /$ moderate & $1.455 \pm 1.103$ & $0.95 \pm 1.461$ & $-2.479 \pm 1.983$ & $0.495 \pm 1.602$ & $-2.825(-5.155-0.81)$ \\
\hline G3/poor & 1.165 & 1.29 & -2.195 & 0.755 & -3.21 \\
\hline Unknown & $1.962 \pm 1.028$ & $-0.285 \pm 2.453$ & $-3.402 \pm 1.446$ & $1.202 \pm 1.156$ & $-2.805(-4.6-1.01)$ \\
\hline P-value & 0.7321 & 0.5453 & 0.2774 & 0.7249 & 0.5092 \\
\hline \multicolumn{6}{|l|}{ Mode of tumor invasion } \\
\hline $1-3$ & $1.283 \pm 1.175$ & $0.92(-2.02-3.695)$ & $-1.584 \pm 1.838$ & $1.285 \pm 2.619$ & $-1.697 \pm 2.059$ \\
\hline $4 C-4 D$ & $1.349 \pm 1.051$ & $0.745(-2.135-1.45)$ & $-3.12 \pm 1.727$ & $0.282 \pm 1.319$ & $-2.447 \pm 1.615$ \\
\hline P-value & 0.8679 & 0.2511 & 0.0168 & 0.0918 & 0.2716 \\
\hline \multicolumn{6}{|l|}{ Depth of tumor } \\
\hline$<5 \mathrm{~mm}$ & $1.289 \pm 1.081$ & $0.785 \pm 1.069$ & $-1.832 \pm 1.941$ & $-1.831 \pm 2.018$ & $1.081 \pm 2.483$ \\
\hline $5 \mathrm{~mm} \leq$ and $<10 \mathrm{~mm}$ & $1.406 \pm 1.905$ & $-0.078 \pm 2.658$ & $-2.955 \pm 1.209$ & $-2.211 \pm 1.676$ & $0.876 \pm 1.751$ \\
\hline P-value & 0.8457 & 0.5638 & 0.2633 & 0.7173 & 0.8730 \\
\hline \multicolumn{6}{|l|}{ Lymphatic invasion } \\
\hline Yes & $1.364 \pm 1.347$ & $0.823 \pm 1.051$ & $-1.039 \pm 1.308$ & $1.343 \pm 3.713$ & $-1.643 \pm 1.413$ \\
\hline No & $1.315 \pm 1.125$ & $0.672 \pm 1.273$ & $-2.028 \pm 1.977$ & $0.955 \pm 2.224$ & $-1.914 \pm 2.075$ \\
\hline Unknown & 0.175 & 1.955 & -2.63 & 4.07 & -0.935 \\
\hline P-value & 0.6153 & 0.5878 & 0.4685 & 0.4339 & 0.8563 \\
\hline \multicolumn{6}{|l|}{ Venous invasion } \\
\hline Yes & $1.199 \pm 0.569$ & $0.066 \pm 1.303$ & $-2.725 \pm 1.534$ & $0.354 \pm 0.720$ & $-2.802 \pm 2.230$ \\
\hline No & $1.309 \pm 1.189$ & $0.788 \pm 1.226$ & $-1.832 \pm 1.939$ & $1.143 \pm 2.530$ & $-1.757 \pm 1.950$ \\
\hline P-value & 0.8396 & 0.2199 & 0.3264 & 0.1278 & 0.2677 \\
\hline \multicolumn{6}{|l|}{ Neural infiltration } \\
\hline Yes & $0.67 \pm 0.630$ & $-0.002 \pm 1.318$ & $-2.995(-6.485-3.285)$ & $1.005 \pm 2.367$ & $-1.651 \pm 2.596$ \\
\hline No & $1.395 \pm 1.164$ & $0.769 \pm 1.221$ & $-2.025(-4.735-0.725)$ & $1.003 \pm 2.435$ & $-1.907 \pm 1.953$ \\
\hline
\end{tabular}


Table II. Continued.

\begin{tabular}{|c|c|c|c|c|c|}
\hline Subgroup & miR-10a & $\operatorname{miR}-10 b$ & miR-196a-5p & $\operatorname{miR}-196 a-3 p$ & $\operatorname{miR}-196 b$ \\
\hline Unknown & 0.175 & 1.955 & -2.63 & 4.07 & -0.935 \\
\hline P-value & 0.2493 & 0.2564 & 0.6001 & 0.4640 & 0.8660 \\
\hline \multicolumn{6}{|l|}{ Smoking } \\
\hline Current or past & $1.120 \pm 1.008$ & $0.235 \pm 1.027$ & $-2.463 \pm 1.949$ & $1.599 \pm 3.009$ & $-1.575(-5.195-0.185)$ \\
\hline Never & $1.407 \pm 1.215$ & $1.011 \pm 1.281$ & $-1.590 \pm 1.836$ & $0.736 \pm 1.956$ & $-1.36(-7.03-2.27)$ \\
\hline P-value & 0.3931 & $\mathbf{0 . 0 3 0 3}$ & 0.1175 & 0.2749 & 0.5622 \\
\hline \multicolumn{6}{|l|}{ Alcohol intake } \\
\hline Current or past & $1,353 \pm 1.340$ & $0.383 \pm 1.270$ & $-2.071 \pm 1.944$ & $1.306 \pm 2.819$ & $-1.23(-5.195-0.185)$ \\
\hline Never & $1.310 \pm 0.998$ & $1.050 \pm 1.130$ & $-1.728 \pm 1.851$ & $0.851 \pm 2.068$ & $-1.49(-7.03-2.27)$ \\
\hline Unknown & $0.794 \pm 0.741$ & $0.371 \pm 1.611$ & $-2.434 \pm 2.704$ & $1.067 \pm 2.707$ & $-4.385(-4.51-0.4325)$ \\
\hline P-value & 0.7335 & 0.1635 & 0.7459 & 0.8194 & 0.5670 \\
\hline
\end{tabular}

$\mathrm{P}<0.05$ indicated statistically significance. Bold values means the significant $\mathrm{P}$-values $(<0.05)$. $\mathrm{n}=50$. The number of subgroups is described in Table I. The expression value of each miR is used $\Delta \Delta$ Cq value. A Gaussian distribution of each group was tested by Shapiro-Wilk test. The homogeneity of the variances was confirmed by Levene test. For data with a Gaussian distribution, the difference between the two groups was demonstrated by Student's t-test or Welch's t-test depending on the homogeneity of the variances. For data that did not conform to a Gaussian distribution, the Mann-Whitney test was applied to compare the samples. When analyzing more than two subgroups, one-way ANOVA or Kruskal-Wallis test was used to test whether the data conformed to a Gaussian distribution. All statistical analyses were performed using the JMP software (JMP Version Pro 12; SAS Institute Inc., Cary, NC, USA). miR, micro RNA; n, number of cases; LNM, lymph node metastasis.

In contrast, targeted miRs could be evaluated by RT-qPCR and were significantly regulated in cancers from patients with delayed LNM when compared to those from patients without LNM in our study. As mentioned above, in the daily practice of OSCC treatment, a potential marker to predict delayed LNM before or immediately after treatment is strongly desired. miR is a useful approach that can easily detect the presence of OSCC not only in fresh tissues but also in blood, saliva, and FFPE tissues (27-30).

When selecting a miR, we suggest that it is important to confirm how many oncogenes or tumor suppressor genes with solid evidence are targeted by that miR. Three reasons for the above suggestion have been presented. First, miRs are often differentially expressed in different cancer conditions such as cancer cells in vitro, tissues in vivo, and human tissues. The functions of miRs are associated with their up- or downregulation (39) and their expression affect several target genes. Many miRs have been reported to be expressed in OSCC $(15,39)$; however, controversially, one study reported that certain miRs were significantly more upregulated in cancer tissues or cells than in normal tissues or cells (39). In contrast, it was reported that these miRs were downregulated in other cancer tissues or cells (39). For example, miR-148b is upregulated in TSCC cell lines (79) but downregulated in Syrian hamster OSCC (80). Similarly, miR-197 was found to be strongly upregulated in LMD of human TSCC (81) but downregulated in human TSCC cell lines (79). Second, one particular miR targets thousands of messenger RNAs (mRNAs); in contrast, one mRNA can be targeted by hundreds of different miRs (31), which contiguously affects several pathways of tumor processes through mRNA (30). Thus, complicated pathways of cancer initiation or progression exist $(25,82)$. Moreover, cancer progression itself has a multistep process associated with multiple alterations of oncogenes and tumor suppressor genes involving miR functions (31). Thus, many miRs are reported as candidates of potential clinical utility, including LNM with OSCC (39,83-86). Third, there are a plethora of miRs related to LNM in OSCC of human patients, in vivo or in vitro, including let-7d (77), let-7g (87), miR-17 and miR-20a (88), miR-21 (89), miR-26b (90), miR-29b (91), miR-31 (92), miR-34a (93), miR-93 (94), miR-134 (95), miR-138 (84), miR-153 (96), miR-155-5p (97), miR-181 (98), miR-196a/b (52), miR-203 (99), miR-205 (83), miR-211 (100), miR-214-3p (10), miR-222 (101), miR-363 (102), miR-372 and miR-373 (85), miR-375 (10), miR-376c-3p (86), miR-491-5p (103), miR-1246 (104), miR-1275 (105). However, no reports have evaluated only 'delayed' LNM of OSCC. In addition, no report has described LNM of early-stage TSCC. Therefore, when choosing miR for a study, we suggest that it is important to confirm how many oncogenes or tumor suppressor genes with solid evidence are targeted by the miR. Among so many miRs related to LNM, we focused on the following $H O X$ gene-related miRs (44-46,52): miR-10a, miR-10b, miR-196a, miR-196b, and miR-615. Those miRs are within the HOX gene clusters that are related to functions of many types of $H \& N$ cancers (44-46).

HOX genes are cancer development genes and tend to differ with regard to their up- or downregulation depending on the cancer site or type (106). HOX genes are suggested to be dysregulated in human OSCC (107). In oral cancer cells or tissues, many HOX genes are upregulated (45). HOX genes are reported as oncogenes that regulate epithelial-mesenchymal transition, cancer invasion, and apoptotic pathways (45). Upregulation of particular $H O X$ genes is associated with upregulation of miRs within each $H O X$ gene. The miRs: miR-10, miR-196, and miR-615 are present within four types of $H O X$ gene clusters: miR-10a and miR-196a-1 are located in $H O X B$ on chromosome 17, miR-10b is located in HOXD on chromosome 2, miR-615 and miR-196a-2 are located in HOXC on chromosome 12, and 
Table III. Association between microRNA-196a-5p $\Delta \Delta$ Cq value regulation and subgroups $(\mathrm{n}=50)$.

Case number of groups

Subgroup

High regulation $(n=25)$

Low regulation $(\mathrm{n}=25)$

P-value

Age

$<60$

$\geq 60$

Gender

Male

Female

Clinical stage

I

II

Local recurrence

Yes

No

Delayed LNM

Yes

No

Distant metastasis

Yes 1

No 24

Histological grade

G1/well

G2/moderate

Mode of tumor invasion

Depth of tumor

$<5 \mathrm{~mm}$

$5 \mathrm{~mm} \leq$ and $<10 \mathrm{~mm}$

Lymphatic invasion

Yes

No

Unknown

Venous invasion

Yes

No

Neural infiltration

Yes

No

Unknown

Smoking

Current or past

Never

Alcohol intake

Current or past 
Table III. Continued.

\section{Case number of groups}

Subgroup

High regulation $(n=25)$

Low regulation $(\mathrm{n}=25)$

P-value

Unknown 1

2

$\mathrm{P}<0.05$ indicated statistically significance. Bold values means the significant $\mathrm{P}$-values $(<0.05) . \mathrm{n}=50$. Differences in the patient numbers between the high $\Delta \Delta \mathrm{Cq}$ value regulation group and the low $\Delta \Delta \mathrm{Cq}$ value regulation group were evaluated by a two-tailed Fisher's exact test. All statistical analyses were performed using the JMP software (JMP Version Pro 12; SAS Institute Inc., Cary, NC, USA). n, number of cases; LNM, lymph node metastasis.
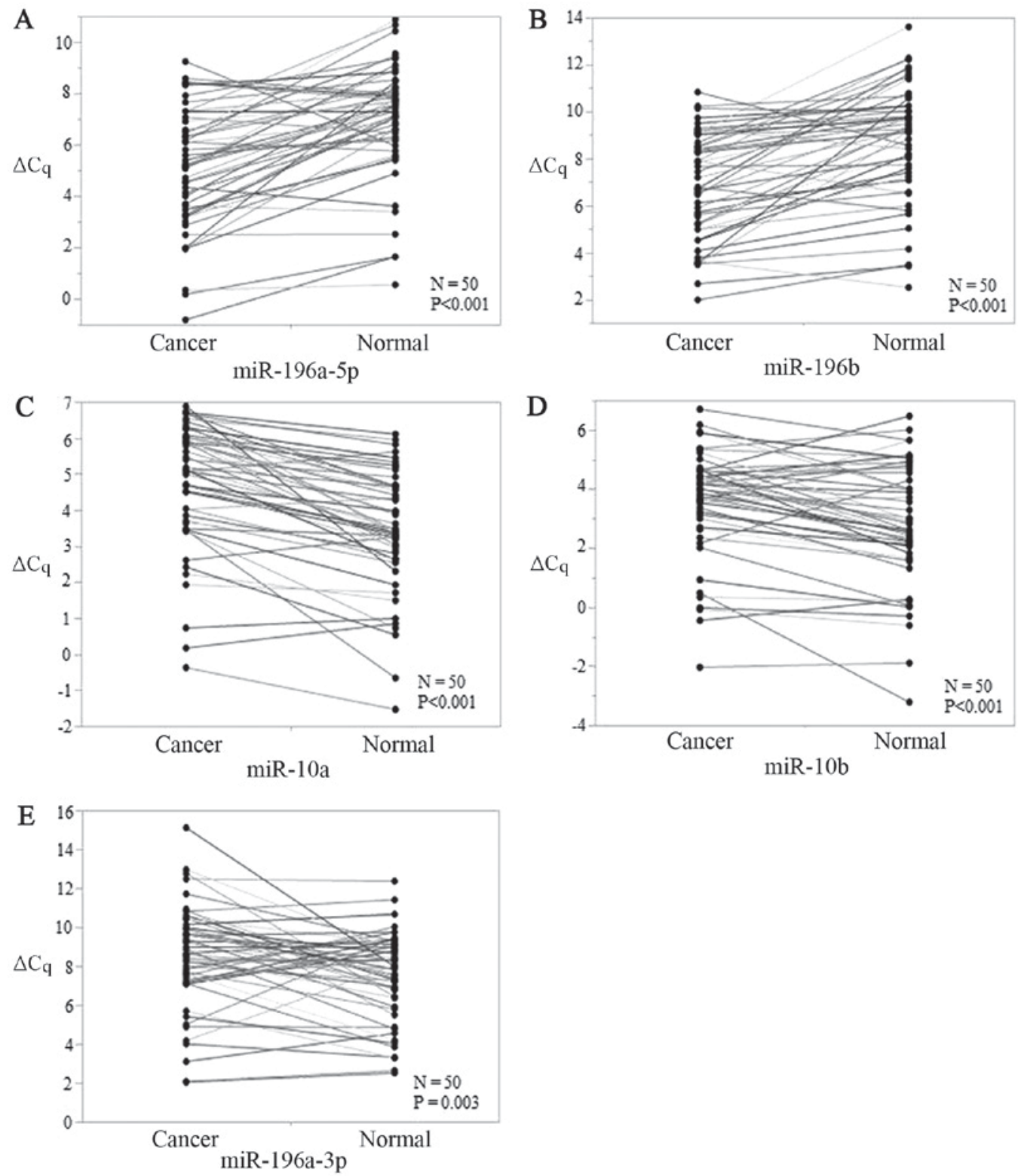

Figure 1. $\Delta$ Cq value expressions of (A-E) 5 candidate miRs [(A) miR-196a-5p, (B) miR-196b, (C) miR-10a, (D) miR-10b, and (E) miR-196a-3p] in early-stage TSCC tissues and paired adjacent normal tissues. P-values of miR-196a-5p, miR-196b, miR-10a, miR-10b, and miR-196a-3p were $<0.001,<0.001,<0.001$, $<0.001$, and 0.003 respectively. miR, microRNA; TSCC, tongue squamous cell carcinoma.

miR-196b is located in HOXA on chromosome $7(45,46,108)$. miR-196a generally means miR-196a-5p. miR-196a-1 and miR-196a-2 have the same sequence; however, they are located on different chromosomes (34). We selected miR-196a-3p (miR passenger strand of miR-196a-2; not present in miR-196a-1) because we attempted to compare the functions of miR-196a-1 

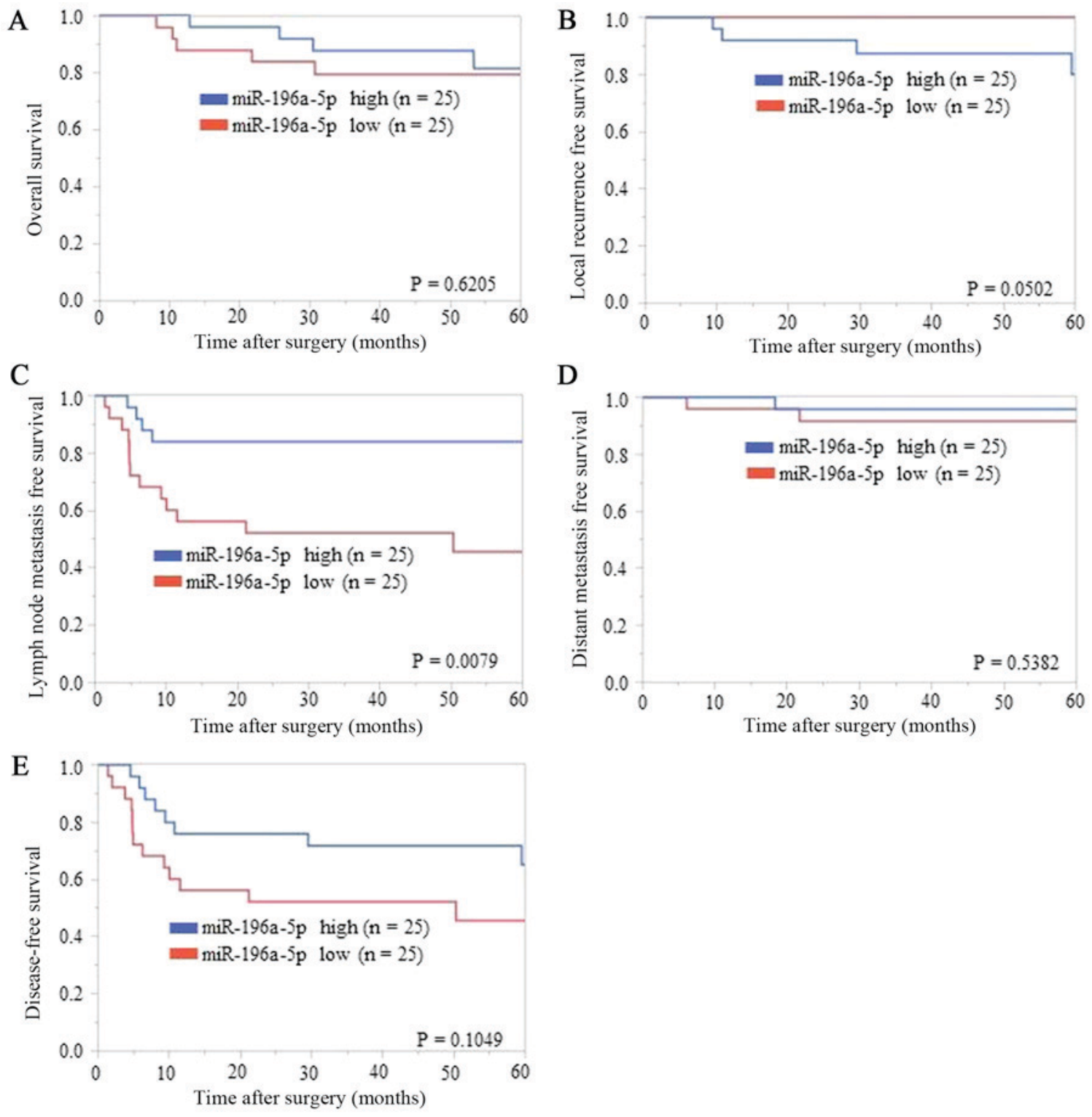

Figure 2. Association of $\Delta \Delta \mathrm{Cq}$ value regulation of miR-196a-5p expression with (A) overall survival, (B) local recurrence-free survival, (C) lymph node metastasis-free survival, (D) distant metastasis-free survival, and (E) disease-free survival. Kaplan-Meier analysis (cut-off: The median $\Delta \Delta$ Cq value) indicated that patients with relatively low $\Delta \Delta \mathrm{Cq}$ value regulation levels of miR-196a-5p experienced significantly shorter lymph node metastasis-free survival than those with high $\Delta \Delta \mathrm{Cq}$ value regulation levels $(\mathrm{P}=0.0079$, log-rank test). Overall survival, local recurrence-free survival, distant metastasis-free survival, and disease-free survival showed no significant differences between low and high groups of miR-196a-5p regulations $(\mathrm{P}=0.6205, \mathrm{P}=0.0502, \mathrm{P}=0.5382$, and $\mathrm{P}=0.1049$, respectively, log-rank test).

and miR-196a-2 (29,34). miR-615 is not reported to be related to cancer (46); therefore, we excluded miR-615 from examination as a prognostic marker because of the sparsity of studies. miR-10a and miR-10b have not been reported to be related to LNM of OSCC to date. However, miR-10 s have been shown to be associated with cancer metastasis. miR-10a was reported to regulate metastasis in various types of cancer (109) and to contribute to LNM of gastric cancer (110), while miR-10b was reported to be significantly upregulated in OSCC cell lines and to promote cell migration and invasion (56). We eventually selected five miRs (miR-10a, miR-10b, miR-196a-5p, miR-196a-3p, and miR-196b) as candidate prognostic markers. In our study, the levels of all five candidate miRs were significantly regulated in cancer tissues when compared to ANTs. This confirmed their possible utility as markers of early-stage TSCC. In our subsequent analyses, we found that miR-196a-5p was a possible prognostic marker of delayed LNM in early-stage TSCC.

In a recent study, significant miR-196a-5p upregulation was observed in early-stage TSCC tissues. Furthermore, miR-196a-5p upregulation increased the risk of delayed LNM and was especially associated with a shorter LNMFS rate in early-stage TSCC. Indeed, our study is not the first to report that miR-196a-5p upregulation is associated with OSCC metastasis $(29,52)$, and we needed previous evidence to rationalize our study of miR-196a-5p. Liu et al reported that miR-196a was significantly upregulated in tumor tissues and plasma in 'all stages' of OSCC (29), suggesting that it might serve as a diagnostic and prognostic marker of LNM. In contrast, we investigated only prognostic markers because diagnostic markers are less important as OSCC is particularly 

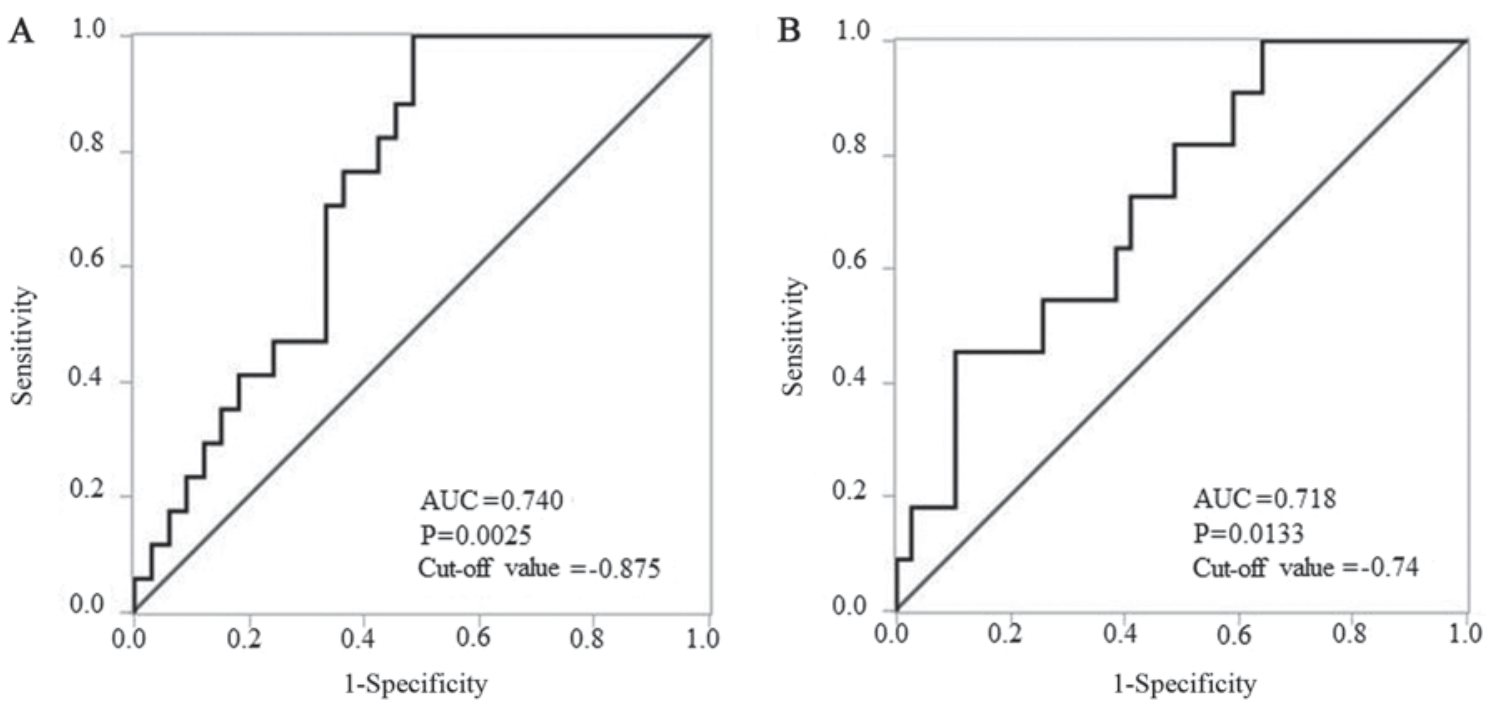

Figure 3. Receiver operating characteristic analysis of $\Delta \Delta \mathrm{Cq}$ values of miR-196a-5p to confirm the prognostic marker in early-stage tongue squamous cell carcinoma. (A) $\Delta \Delta \mathrm{Cq}$ values revealed that miR-196a-5p levels had a P-value of 0.0025 , an AUC of 0.740 , and a cut-off value of -0.875 to distinguish lymph node metastasis. (B) $\Delta \Delta \mathrm{Cq}$ values revealed that miR-196a-5p levels had a P-value of 0.0133 , an AUC of 0.718 , and the cut-off value of -0.74 to distinguish YK grade 4C-4D from YK grade 1-3. AUC, area under the curve.

easy to detect clinically. We also limited the study to patients with early-stage TSCC for four reasons. First, miR expression in cancer tissue is specific to site or cancer type. miRs expressed in the tongue and in other sites of the oral cavity differ (26). Furthermore, Harris et al reported that the expression of most miRs was different in three sites of the H\&N region via microarray analysis of human SCC tissue (111). Moreover, miRs expressions of H\&N SCC were different compared to those of H\&N ACC using microarray analysis (112). Second, miR expression can be different between early-stage and advanced-stage cancer, and this has been reported previously in microarray studies $(58,89)$. Despite being the same type of cancer, early-stage and advanced-stage OSCCs showed significantly different miR-31 expression levels (92). Other studies reported distinct expression modes in oral cancer and premalignant disease (such as dysplasia and leukoplakia) $(113,114)$. The expressions of some genes are distinct between oral carcinoma in situ and early-stage OSCC (115). Therefore, OSCC appears and progresses by complicated multi-stage processes $(39,116)$. Thus, we suggest that early-stage and advanced-stage TSCC have different miRs impacting and regulating pathways. Furthermore, we excluded premalignant disease and carcinoma in situ in the current study. Third, as mentioned above, early-stage TSCC is one of the most common H\&N cancers, and TSCC is the most aggressive type of OSCC (21). Fourth, it is relatively easy in early-stage OSCC to distinguish neck LNM from local recurrence. In contrast, it is often difficult to classify advanced cancer as one or another relapse, especially after neck dissection (117). We speculate that limiting our study to early-stage TSCC helped to effectively evaluate only delayed LNM or local recurrence and tumor-specific miRs.

miR-196a-5p targets several HOX genes $(35,118)$ and directly targets many other genes (35). Lately, it has been reported that miR-196-5p is aberrantly expressed in many kinds of cancers and targets many genes, including several genes of the HOX family, and functions, such as cancer proliferation, metastasis, and invasion $(34,46)$. miR-196a-5p is upregulated in OSCC tissues and cells, and its inhibition of mRNA translation contributes to many cancer processes (cell proliferation, migration, and invasion), as an oncogene $(29,35,52)$. A certain $H O X$ gene upregulation indicates miRs located in the $H O X$ gene. Therefore, cancer progression by $H O X$ gene upregulation as an oncogene is related to miR-196a-5p upregulation in H\&N SCC (45). Furthermore, HOX genes are related to HOTAIR $(119,120)$, which exists upstream of miR-196a-2 and has been reported to be highly regulated in OSCC and significantly upregulated in cancers with LNM when compared to the regulation in cancers without metastasis $(35,121)$. As an oncogene of $H \& N$ cancer and oral cancer, miR-196-5p targets many genes, as described above $(34,35)$. Annexin Al is targeted by miR-196a-5p over-regulation and is related to metastasis as well as proliferation, invasion, and radio resistance of H\&N cancer (53). NME4 was directly inhibited by miR-196a-5p with significant upregulation in cancer tissues and was correlated with neck LNM of oral cancer (52). MAMDC2 has been reported as a novel direct target of miR-196a-5p in $\mathrm{H} \& \mathrm{~N}$ SCC (46). All the above-mentioned genes are regulated and caused LNM by upregulation of miR-196a-5p, which is similar to our results. Based on the results of our study, miR-196a-5p can be a potential prognostic marker of delayed LNM. In addition, future studies are required to confirm whether miR-196-5p can be used as a therapeutic marker for OSCC metastasis, as reported by Chen et al (35).

The use of a biomarker for diagnosis or prognosis of cancer is a general concept (3). Several molecular markers (e.g., protein, mRNA, and miR) have been studied by using tissue, blood, and saliva (113). However, a reliable biomarker that can detect cancer early, provide a more accurate diagnosis, predict prognosis, and allow the patient to receive the best treatment is strongly desired (113). As described above, for OSCC patients, it is critically more important to identify prognostic markers than diagnostic markers. To establish a miR as a biomarker with a highly reliable assay system for routine clinical purposes, four conditions are needed. One, the examination of the biomarker 
should be easy and the method should be reproducible for clinical use (122). Two, many examination cases are needed $(10,54)$. Three, noninvasive methods should be preferred (123). Four, tissues should be accurately collected (122). Moreover, as described above, we should pay attention to the characteristics of the miRs. The biomarker should be specific for early-stage TSCC and not for other H\&N cancers because miR expression is stage- and site-specific, as well as cancer-specific $(26,92,111$, 112). In the current study, the tissues of patients were accurately collected, and there were epithelial tumor tissues and epithelial ANTs collected by LMD (81). The FFPE examination was noninvasive, and it is relatively easy to increase the number of cases than other type of samples. On the other hand, fresh tissue was collected with an invasive (scalpel) method and, sometimes, epithelial tissues were collected along with stroma tissues, making the examination results uncertain (122). In the future, we plan to confirm the current results in a prospective study. Recently, Adami et al reported the advantages of brush biopsy (noninvasive) of oral cancer (122). This method allows easy assessment of the difference in OSCC tissue and epithelial ANT for pretreatment timing (124), and accumulation of cases is strongly expected in the future (123).

ROC analysis is a standard approach to identify a detection cut-off for a disease biomarker (125). In ROC analysis, the AUC can be calculated to evaluate the power of an assay system to accurately distinguish between true and false results for diseases, especially cancer $(125,126)$. As used by many researchers, the AUC scale was defined by Hosmer et al (127): if AUC $=0.5$, no discrimination; if $0.5<\mathrm{AUC}<0.7$, poor discrimination; if $0.7 \leq \mathrm{AUC}<0.8$, acceptable discrimination; if $0.8 \leq \mathrm{AUC}<0.9$, excellent discrimination; and if $\mathrm{AUC} \geq 0.9$, discrimination is considered. Based on our results, miR-196-5p can be a potential prognostic marker. In our ROC analysis, our results were statistically significant according to the findings of previous studies on biomarkers $(126,128,129)(\mathrm{P}<0.05$ and AUC $>0.7)$.

$\mathrm{miR}$ is a useful marker that can easily detect the expression of OSCC not only in fresh tissues but also blood, saliva, and FFPE tissues (27-30). Among these tissues, FFPE tissues are useful to evaluate miR expressions $(57,58,130)$. Very old FFPE tissues, such as those obtained 10-19 years previously, have been used in miR study $(28,131,132)$. Therefore, we could use old tissue for evaluation, with the oldest sample being 12 years old. Certainly, our total RNA amount and density were low by using BioSpec-nano; however, in all patients, the Cq values of RNU44 and RNU48 could be determined (Cq values=23.4-36.58) for use. mRNA in FFPE tissues is difficult to examine using the above method because formalin fixation reduces the recovery and quality of RNA (131). In contrast, miR in FFPE tissues can be examined because miRs are small and are protected by the RISC complex (133). miRs in FFPE tissues are reportedly robust and well-regulated in RT-qPCR and frozen tissue sample (131). FFPE tissues are valuable for conducting retrospective studies of human cancer (131). Therefore, many miR studies using FFPE can be accumulated in the future.

The present study has some limitations. First, the results of the present study might be limited because of the retrospective study design and inclusion of only 50 patients. Additionally, fresh tissues were not analyzed. However, the number of patients appeared to be sufficient according to previous studies $(83-85,134,135)$. Further studies that assess fresh cancer tissues and include a higher number of patients should be performed. Second, the study was biased as it investigated only miR-10a, miR-10b, miR-196a-5p, miR-196a-3p, and miR-196b. Third, differential expression did not allow identification of regulatory mechanisms, particularly when the activities/expressions of the targets/pathway output were not investigated. We suggest that one miR repressed many target genes; thus, studies are needed to evaluate $\mathrm{miR}$ with solid evidence from past studies rather than those involving unknown new target genes and pathways. In contrast, the main strengths of this study are that it provides data to indicate miR-196a as an acceptable marker and that it can be considered as a pilot study for similar studies in the future. FFPE is considered useful to evaluate the expression levels of miRs.

In conclusion, to the best of our knowledge, this is the first study to examine LNM-related miR in early-stage TSCC and also the first miR study of 'delayed' LNM of H\&N cancer. In addition, our findings revealed that miR-196a-5p is a potential new biomarker for the prognosis of TSCC and our results serve as a foundation for further studies (not only fresh tissues and FFPE but also blood and saliva of preoperative and postoperative samples) to evaluate the utility of this $\mathrm{miR}$ in the prediction of delayed LNM during the treatment of patients with early-stage TSCC. Furthermore, the results enhanced efforts to prevent metastasis when combined with close follow-up and aggressive adjuvant therapy or END. Moreover, our data will serve as a foundation for future studies to evaluate whether miR-196a-5p can serve as a therapeutic marker for preventing metastasis.

\section{Acknowledgements}

The authors would like to thank Reika Takamatsu and Toshiyuki Nishihira (Department of Pathology and Oncology, Graduate School of Medicine, University of the Ryukyus) for the technical support.

\section{References}

1. IARC: GLOBOCAN 2012: Estimated Cancer Incidence, Mortality and Prevalence Worldwide in 2012. http://globocan.iarc. fr/Pages/fact_sheets_population.aspx. Accessed February 22, 2017.

2. Brierley JD, Gospodarowicz M and Wittekind C (eds): Lip and Oral Cavity. In: TNM Classification of Malignant Tumours. 8th edition. Wiley Blackwell, New York, NY, pp18-21, 2016.

3. Sinevici N and O'sullivan J: Oral cancer: Deregulated molecular events and their use as biomarkers. Oral Oncol 61: 12-18, 2016.

4. Siegel RL, Miller KD and Jemal A: Cancer statistics, 2016. CA Cancer J Clin 660: 7-30, 2016.

5. Jemal A, Murray T, Ward E, Samuels A, Tiwari RC, Ghafoor A, Feuer EJ and Thun MJ: Cancer statistics, 2005. CA Cancer J Clin 55, 2005.

6. Parker SL, Tong T, Bolden S and Wingo PA: Cancer statistics, 1996. CA Cancer J Clin 46: 5-27, 1996.

7. LiZ, Wang Y, Qiu J,Li Q, Yuan C, Zhang W, Wang D, Ye J, Jiang H Yang $\mathrm{J}$ and Cheng J: The polycomb group protein EZH2 is a novel therapeutic target in tongue cancer. Oncotarget 4: 2532-2549, 2013.

8. Wang C, Huang H, Huang Z, Wang A, Chen X, Huang L, Zhou X and Liu X: Tumor budding correlates with poor prognosis and epithelial-mesenchymal transition in tongue squamous cell carcinoma. J Oral Pathol Med 40: 545-551, 2011.

9. Schwam ZG and Judson BL: Improved prognosis for patients with oral cavity squamous cell carcinoma: Analysis of the national cancer database 1998-2006. Oral Oncol 52: 45-51, 2016.

10. Yoon AJ, Wang S, Shen J, Robine N, Philipone E, Oster MW, Nam A and Santella RM: Prognostic value of miR-375 and miR-214-3p in early stage oral squamous cell carcinoma. Am J Transl Res 6: 580-592, 2014. 
11. National ComprehensiveCancer Network: NCCN Clinical Practice Guidelines in Oncology (NCCN Guidelines): Head and Neck Cancers 2017. https://www.nccn.org/professionals/physician_gls/pdf/head-and-neck.pdf. Accessed February 24, 2017.

12. Rogers SN, Brown JS, Woolgar JA, Lowe D, Magennis P, Shaw RJ, Sutton D, Errington D and Vaughan D: Survival following primary surgery for oral cancer. Oral Oncol 45: 201-211, 2009.

13. Kelner N, Vartanian JG, Pinto CA, Coutinho-Camillo CM and Kowalski LP: Does elective neck dissection in T1/T2 carcinoma of the oral tongue and floor of the mouth influence recurrence and survival rates? Br J Oral Maxillofac Surg 52: 590-597, 2014.

14. Ong HS, Gokavarapu S, Wang LZ, Tian Z and Zhang CP: Low pretreatment lymphocyte-monocyte ratio and high platelet-lymphocyte ratio indicate poor cancer outcome in early tongue cancer. J Oral Maxillofac Surg 75: 1762-1774, 2017.

15. Yu X and Li Z: MicroRNA expression and its implications for diagnosis and therapy of tongue squamous cell carcinoma. J Cell Mol Med 20: 10-16, 2016

16. Seki M, Sano T, Yokoo S and Oyama T: Tumour budding evaluated in biopsy specimens is a useful predictor of prognosis in patients with cNO early stage oral squamous cell carcinoma. Histopathology 70: 869-879, 2017.

17. Ariji Y, Goto M, Fukano H, Sugita Y, Izumi M and Ariji E: Role of intraoral color Doppler sonography in predicting delayed cervical lymph node metastasis in patients with early-stage tongue cancer: A pilot study. Oral Surg Oral Med Oral Pathol Oral Radiol 119: 246-253, 2015.

18. Habu N, Imanishi Y, Kameyama K, et al: Expression of Oct3/4 and Nanog in the head and neck squamous carcinoma cells and its clinical implications for delayed neck metastasis in stage I/II oral tongue squamous cell carcinoma. BMC Cancer 15: 730, 2015.

19. Goto M, Hanai N, Ozawa T, Hirakawa H, Suzuki H, Hyodo I, Kodaira T, Ogawa T, Fujimoto Y, Terada A, et al: Prognostic factors and outcomes for salvage surgery in patients with recurrent squamous cell carcinoma of the tongue. Asia Pac J Clin Oncol 12: e141-e148, 2016.

20. Luksic I and Suton P: Predictive markers for delayed lymph node metastases and survival in early-stage oral squamous cell carcinoma. Head Neck 39: 694-701, 2017.

21. Almangush A, Coletta RD, Bello IO, Bitu C, Keski-Säntti H, Mäkinen LK, Kauppila JH, Pukkila M, Hagström J, Laranne J, et al: A simple novel prognostic model for early stage oral tongue cancer. Int J Oral Maxillofac Surg 44: 143-150, 2015.

22. Montebugnoli L, Gissi DB, Flamminio F, Gentile L, Dallera V, Leonardi E, Beccarini T and Foschini MP: Clinicopathologic parameters related to recurrence and locoregional metastasis in 180 oral squamous cell carcinomas. Int J Surg Pathol 22: 55-62, 2014.

23. Dunkel J, Vaittinen S, Grénman R, Kinnunen I and Irjala H: Prognostic markers in stage I oral cavity squamous cell carcinoma. Laryngoscope 123: 2435-2441, 2013.

24. Harada Y, Izumi H, Noguchi H, Kuma A, Kawatsu Y, Kimura T, Kitada S, Uramoto H, Wang KY, Sasaguri Y, et al: Erratum to: Strong expression of polypeptide $\mathrm{N}$-acetylgalactosaminyltransferase 3 independently predicts shortened disease-free survival in patients with early stage ora squamous cell carcinoma. Tumour Biol 36: 10003-10004, 2015.

25. Villegas-Ruiz V, Juárez-Méndez S, Pérez-González OA, Arreola H, Paniagua-García L, Parra-Melquiadez M, Peralta-Rodríguez R, López-Romero R, Monroy-García A, Mantilla-Morales A, et al: Heterogeneity of microRNAs expression in cervical cancer cells: Over-expression of miR-196a. Int J Clin Exp Pathol 7: 1389-1401, 2014.

26. Boldrup L, Coates PJ, Laurell G, Wilms T, Fahraeus R and Nylander K: Downregulation of miRNA-424: A sign of field cancerisation in clinically normal tongue adjacent to squamous cell carcinoma. Br J Cancer 112: 1760-1765, 2015

27. Liu X, Wang A, Heidbreder CE, Jiang L, Yu J, Kolokythas A, Huang L, Dai Y and Zhou X: MicroRNA-24 targeting RNA-binding protein DND1 in tongue squamous cell carcinoma. FEBS Lett 584: 4115-4120, 2010.

28. Rosenfeld N, Aharonov R, Meiri E, Rosenwald S, Spector Y, Zepeniuk M, Benjamin H, Shabes N, Tabak S, Levy A, et al: MicroRNAs accurately identify cancer tissue origin. Nat Biotechnol 26: 462-469, 2008.

29. Liu CJ, Tsai MM, Tu HF, Lui MT, Cheng HW and Lin SC: miR-196a overexpression and miR-196a2 gene polymorphism are prognostic predictors of oral carcinomas. Ann Surg Oncol. Suppl 3 (20 Suppl): S406-S414, 2013.
30. Liu CJ, Lin SC, Yang CC, Cheng HW and Chang KW: Exploiting salivary miR-31 as a clinical biomarker of oral squamous cell carcinoma. Head Neck 34: 219-224, 2012.

31. Di Leva G, Garofalo M and Croce CM: MicroRNAs in cancer. Annu Rev Pathol 9: 287-314, 2014.

32. Reddy KB: MicroRNA (miRNA) in cancer. Cancer Cell Int 15: $38,2015$.

33. Lin S and Gregory RI: MicroRNA biogenesis pathways in cancer. Nat Rev Cancer 15: 321-333, 2015.

34. Lu YC, Chang JT, Chan EC, Chao YK, Yeh TS, Chen JS and Cheng AJ: miR-196, an emerging cancer biomarker for digestive tract cancers. J Cancer 7: 650-655, 2016.

35. Chen ZY, Chen X and Wang ZX: The role of microRNA-196a in tumorigenesis, tumor progression, and prognosis. Tumour Biol: Oct 18,2016 (Epub ahead of print).

36. Friedman RC, Farh KK, Burge CB and Bartel DP: Most mammalian mRNAs are conserved targets of microRNAs. Genome Res 19: 92-105, 2009.

37. Nohata N, Hanazawa T, Kinoshita T, Okamoto Y and Seki N: MicroRNAs function as tumor suppressors or oncogenes: Aberrant expression of microRNAs in head and neck squamous cell carcinoma. Auris Nasus Larynx 40: 143-149, 2013.

38. Lamouille S, Subramanyam D, Blelloch R and Derynck R Regulation of epithelial-mesenchymal and mesenchymal-epithelial transitions by microRNAs. Curr Opin Cell Biol 25: 200-207, 2013.

39. Yu T, Li C, Wang Z, Liu K, Xu C, Yang Q, Tang Y and Wu Y: Non-coding RNAs deregulation in oral squamous cell carcinoma: Advances and challenges. Clin Transl Oncol 18: 427-436, 2016.

40. Tu HF, Lin SC and Chang KW: MicroRNA aberrances in head and neck cancer: Pathogenetic and clinical significance. Curr Opin Otolaryngol Head Neck Surg 21: 104-111, 2013.

41. Zhang H, Li Y and Lai M: The microRNA network and tumor metastasis. Oncogene 29: 937-948, 2010.

42. Bracken CP, Gregory PA, Khew-Goodall Y and Goodall GJ: The role of microRNAs in metastasis and epithelial-mesenchymal transition. Cell Mol Life Sci 66: 1682-1699, 2009.

43. Kim KY, Lee GY and Cha IH: Biomarker detection for the diagnosis of lymph node metastasis from oral squamous cell carcinoma. Oral Oncol 48: 311-319, 2012.

44. Severino P, Brüggemann H, Andreghetto FM, Camps C, Klingbeil Mde F, de Pereira WO, Soares RM, Moyses R, Wünsch-Filho V, Mathor MB, et al: MicroRNA expression profile in head and neck cancer: HOX-cluster embedded microRNA-196a and microRNA-10b dysregulation implicated in cell proliferation. BMC Cancer 13: 533, 2013.

45. Platais C, Hakami F, Darda L, Lambert DW, Morgan R and Hunter KD: The role of HOX genes in head and neck squamous cell carcinoma. J Oral Pathol Med 45: 239-247, 2016.

46. Darda L, Hakami F, Morgan R, Murdoch C, Lambert DW and Hunter KD: The role of HOXB9 and miR-196a in head and neck squamous cell carcinoma. PLoS One 10: e0122285, 2015.

47. Jiang Y, Zhang Y, Li F, Du X and Zhang J: CDX2 inhibits pancreatic adenocarcinoma cell proliferation via promoting tumor suppressor miR-615-5p. Tumour Biol 37: 1041-1049, 2016.

48. Pearson CE: Co-opting endogenous microRNAs for therapy. Nat Med 18: 1011-1012, 2012

49. Hoss AG, Kartha VK, Dong X, Latourelle JC, Dumitriu A, Hadzi TC, Macdonald ME, Gusella JF, Akbarian S, Chen JF, et al: MicroRNAs located in the Hox gene clusters are implicated in huntington's disease pathogenesis. PLoS Genet 10: e1004188, 2014.

50. Shan Q, Zheng G, Zhu A, Cao L, Lu J, Wu D, Zhang Z, Fan S, Sun C, Hu B, et al: Epigenetic modification of miR-10a regulates renal damage by targeting CREB1 in type 2 diabetes mellitus. Toxicol Appl Pharmacol 306: 134-143, 2016.

51. Bourguignon LY, Wong G and Shiina M: Up-regulation of histone methyltransferase, DOT1L, by matrix hyaluronan promotes MicroRNA-10 expression leading to tumor cell invasion and chemoresistance in cancer stem cells from head and neck squamous cell carcinoma. J Biol Chem 291: 10571-10585, 2016.

52. Lu YC, Chang JT, Liao CT, Kang CJ, Huang SF, Chen IH, Huang CC, Huang YC,Chen WH,TsaiCY, et al: OncomiR-196 promotes an invasive phenotype in oral cancer through the NME4-JNK-TIMP1-MMP signaling pathway. Mol Cancer 13: 218, 2014.

53. Suh YE, Raulf N, Gäken J, Lawler K, Urbano TG, Bullenkamp J, Gobeil S, Huot J, Odell E and Tavassoli M: MicroRNA-196a promotes an oncogenic effect in head and neck cancer cells by suppressing annexin $\mathrm{A} 1$ and enhancing radioresistance. Int $\mathrm{J}$ Cancer 137: 1021-1034, 2015 
54. Saito K, Inagaki K, Kamimoto T, Ito Y, Sugita T, Nakajo S, Hirasawa A, Iwamaru A, Ishikura T, Hanaoka $\mathrm{H}$, et al: MicroRNA-196a is a putative diagnostic biomarker and therapeutic target for laryngeal cancer. PLoS One 8: e71480, 2013.

55. Kozaki K, Imoto I, Mogi S, Omura K and Inazawa J: Exploration of tumor-suppressive microRNAs silenced by DNA hypermethylation in oral cancer. Cancer Res 68: 2094-2105, 2008.

56. Lu YC, Chen YJ, Wang HM, Tsai CY, Chen WH, Huang YC, Fan KH, Tsai CN, Huang SF, Kang CJ, et al: Oncogenic function and early detection potential of miRNA-10b in oral cancer as identified by microRNA profiling. Cancer Prev Res (Phila) 5: 665-674, 2012

57. Ganci F, Sacconi A, Manciocco V, Sperduti I, Battaglia P, Covello R, Muti P, Strano S, Spriano G, Fontemaggi G, et al: MicroRNA expression as predictor of local recurrence risk in oral squamous cell carcinoma. Head Neck 38: E189-E197, 2016.

58. Sasahira T, Kurihara M, Bhawal UK, Ueda N, Shimomoto T, Yamamoto K, Kirita T and Kuniyasu H: Downregulation of miR-126 induces angiogenesis and lymphangiogenesis by activation of VEGF-A in oral cancer. Br J Cancer 107: 700-706, 2012.

59. Zhang X, Yang H, Lee JJ, Kim E, Lippman SM, Khuri FR Spitz MR, Lotan R, Hong WK and Wu X: MicroRNA-related genetic variations as predictors for risk of second primary tumor and/or recurrence in patients with early-stage head and neck cancer. Carcinogenesis 31: 2118-2123, 2010

60. Gombos K, Horváth R, Szele E, Juhász K, Gocze K, Somlai K, Pajkos G, Ember I and Olasz L: miRNA expression profiles of oral squamous cell carcinomas. Anticancer Res 33: 1511-1517, 2013.

61. Kina S, Nakasone T, Kinjo T, Maruyama T, Kawano T and Arasaki A: Impact of metronomic neoadjuvant chemotherapy on early tongue cancer. Cancer Chemother Pharmacol 78: 833-840, 2016.

62. Peisker A, Raschke GF, Guentsch A, Luepke P, Roshanghias K and Schultze-Mosgau S: Evaluation of a post-treatment follow-up program in patients with oral squamous cell carcinoma. Clin Oral Investig 21: 135-141, 2017.

63. Yanamoto S, Yamada S, Takahashi H, Kawasaki G, Ikeda H, Shiraishi T, Fujita S, Ikeda T, Asahina I and Umeda M: Predictors of locoregional recurrence in T1-2N0 tongue cancer patients. Pathol Oncol Res 19: 795-803, 2013.

64. Johnson N, Franceschi S, Ferlay J, Ramadas K, Schmid S, MacDonald DG, Bouquot JE and Slootweg PJ: Squamous cell carcinoma. In: World Health Organization Classification of Tumours. Pathology \& Genetics Head and Neck Tumours Barnes C, Eveson JW, Reichart P and Sidransky D (eds). IARC Press, Lyon, pp168-175, 2005 .

65. Yamamoto E, Kohama G, Sunakawa $\mathrm{H}$, Iwai $\mathrm{M}$ and Hiratsuka $\mathrm{H}$ : Mode of invasion, bleomycin sensitivity and clinical course in squamous cell carcinoma of the oral cavity. Cancer 51: 2175-2180, 1983.

66. Huang SH, Hwang D, Lockwood G, Goldstein DP and O'Sullivan B: Predictive value of tumor thickness for cervical lymph-node involvement in squamous cell carcinoma of the oral cavity: A meta-analysis of reported studies. Cancer 115 : 1489-1497, 2009.

67. Zeka F, Vanderheyden K, De Smet E, Cuvelier CA, Mestdagh P and Vandesompele J: Straightforward and sensitive RT-qPCR based gene expression analysis of FFPE samples. Sci Rep 6 : 21418, 2016.

68. Nagao Y, Hisaoka M, Matsuyama A, Kanemitsu S, Hamada T, Fukuyama T, Nakano R, Uchiyama A, Kawamoto M, Yamaguchi K, et al: Association of microRNA-21 expression with its targets, PDCD4 and TIMP3, in pancreatic ductal adenocarcinoma. Mod Pathol 25: 112-121, 2012.

69. Livak KJ and Schmittgen TD: Analysis of relative gene expression data using real-time quantitative PCR and the 2(-Delta Delta C(T)) method. Methods 25: 402-408, 2001.

70. Fanale D, Amodeo V, Bazan V, Insalaco L, Incorvaia L, Barraco N, Castiglia M, Rizzo S, Santini D, Giordano A, et al: Can the microRNA expression profile help to identify novel targets for zoledronic acid in breast cancer? Oncotarget 7 : 29321-29332, 2016.

71. McCall MN, McMurray HR, Land H and Almudevar A: On non-detects in qPCR data. Bioinformatics 30: 2310-2316, 2014

72. Lee RC, Feinbaum RL and Ambros V: The C. elegans heterochronic gene lin-4 encodes small RNAs with antisense complementarity to lin-14. Cell 75: 843-854, 1993.

73. Scott SE, Grunfeld EA and McGurk M: The idiosyncratic relationship between diagnostic delay and stage of oral squamous cell carcinoma. Oral Oncol 41: 396-403, 2005.
74. Mitani S, Tomioka T, Hayashi R, Ugumori T, Hato N and Fujii S: Anatomic invasive depth predicts delayed cervical lymph node metastasis of tongue squamous cell carcinoma. Am J Surg Pathol 40: 934-942, 2016.

75. Orabona GD, Bonavolontà P, Maglitto F, Friscia M, Iaconetta G and Califano L: Neck dissection versus 'watchful-waiting' in early squamous cell carcinoma of the tongue our experience on 127 cases. Surg Oncol 25: 401-404, 2016.

76. D'Cruz AK, Vaish R, Kapre N, Dandekar M, Gupta S, Hawaldar R, Agarwal JP, Pantvaidya G, Chaukar D, Deshmukh A, et al: Elective versus therapeutic neck dissection in node-negative oral cancer. N Engl J Med 373: 521-529, 2015.

77. Irani S: miRNAs signature in head and neck squamous cell carcinoma metastasis: A literature review. J Dent (Shiraz) 17: 71-83, 2016

78. Ganly I, Goldstein D, Carlson DL, Patel SG, O'Sullivan B, Lee N, Gullane P and Shah JP: Long-term regional control and survival in patients with 'low-risk,' early stage oral tongue cancer managed by partial glossectomy and neck dissection without postoperative radiation: The importance of tumor thickness. Cancer 119: 1168-1176, 2013.

79. Hebert C, Norris K, Scheper MA, Nikitakis N and Sauk JJ: High mobility group A2 is a target for miRNA-98 in head and neck squamous cell carcinoma. Mol Cancer 6: 5, 2007.

80. Yu T, Wang XY, Gong RG, Li A, Yang S, Cao YT, Wen YM, Wang CM and Yi XZ: The expression profile of microRNAs in a model of 7,12-dimethyl-benz [a]anthrance-induced oral carcinogenesis in Syrian hamster. J Exp Clin Cancer Res 28: 64, 2009.

81. Wong TS, Liu XB, Chung-Wai Ho A, Po-Wing Yuen A, Wai-Man $\mathrm{Ng}$ R and Ignace Wei W: Identification of pyruvate kinase type M2 as potential oncoprotein in squamous cell carcinoma of tongue through microRNA profiling. Int J Cancer 123: 251-257, 2008.

82. Grizzi F, Di Ieva A, Russo C, Frezza EE, Cobos E, Muzzio PC and Chiriva-Internati M: Cancer initiation and progression: An unsimplifiable complexity. Theor Biol Med Model 3: 37, 2006.

83. Brito BL, Lourenço SV, Damascena AS, Kowalski LP, Soares FA and Coutinho-Camillo CM: Expression of stem cell-regulating miRNAs in oral cavity and oropharynx squamous cell carcinoma. J Oral Pathol Med 45: 647-654, 2016.

84. Manikandan M, Deva Magendhra Rao AK, Rajkumar KS, Rajaraman R and Munirajan AK: Altered levels of miR-21, miR-125b-2*, miR-138, miR-155, miR-184 and miR-205 in oral squamous cell carcinoma and association with clinicopathological characteristics. J Oral Pathol Med 44: 792-800, 2015.

85. Tu HF, Chang KW, Cheng HW and Liu CJ: Upregulation of miR-372 and -373 associates with lymph node metastasis and poor prognosis of oral carcinomas. Laryngoscope 125: E365-E370, 2015.

86. Chang WM, Lin YF, Su CY, Peng HY, Chang YC, Lai TC, Wu GH, Hsu YM, Chi LH, Hsiao JR, et al: Dysregulation of RUNX2/activin-A axis upon miR-376c downregulation promotes lymph node metastasis in head and neck squamous cell carcinoma. Cancer Res 76: 7140-7150, 2016.

87. Peng SC, Liao CT, Peng CH, Cheng AJ, Chen SJ, Huang CG, Hsieh WP and Yen TC: MicroRNAs MiR-218, MiR-125b, and Let- $7 \mathrm{~g}$ predict prognosis in patients with oral cavity squamous cell carcinoma. PLoS One 9: e102403, 2014.

88. Chang CC, Yang YJ, Li YJ, Chen ST, Lin BR, Wu TS, Lin SK, Kuo MY and Tan CT: MicroRNA-17/20a functions to inhibit cell migration and can be used a prognostic marker in oral squamous cell carcinoma. Oral Oncol 49: 923-931, 2013.

89. Li J, Huang H, Sun L, Yang M, Pan C, Chen W, Wu D, Lin Z, Zeng C, Yao Y, et al: MiR-21 indicates poor prognosis in tongue squamous cell carcinomas as an apoptosis inhibitor. Clin Cancer Res 15: 3998-4008, 2009.

90. Cao J, Guo T, Dong Q, Zhang J and Li Y: miR-26b is downregulated in human tongue squamous cell carcinoma and regulates cell proliferation and metastasis through a COX-2-dependent mechanism. Oncol Rep 33: 974-980, 2015.

91. Yang CN, Deng YT, Tang JY, Cheng SJ, Chen ST, Li YJ, Wu TS, Yang MH, Lin BR, Kuo MY, et al: MicroRNA-29b regulates migration in oral squamous cell carcinoma and its clinical significance. Oral Oncol 51: 170-177, 2015.

92. Siow MY, Ng LP, Vincent-Chong VK, Jamaludin M, Abraham MT, Abdul Rahman ZA, Kallarakkal TG, Yang YH, Cheong SC and Zain RB: Dysregulation of miR-31 and miR-375 expression is associated with clinical outcomes in oral carcinoma. Oral Dis 20: $345-351,2014$ 
93. Jia LF, Wei SB, Mitchelson K, Gao Y, Zheng YF, Meng Z, Gan YH and Yu GY: miR-34a inhibits migration and invasion of tongue squamous cell carcinoma via targeting MMP9 and MMP14. PLoS One 9: e108435, 2014

94. Li G, Ren S, Su Z, Liu C, Deng T, Huang D, Tian Y, Qiu Y and Liu Y: Increased expression of miR-93 is associated with poor prognosis in head and neck squamous cell carcinoma. Tumour Biol 36: 3949-3956, 2015.

95. Liu CJ, Shen WG, Peng SY, Cheng HW, Kao SY, Lin SC and Chang KW: miR-134 induces oncogenicity and metastasis in head and neck carcinoma through targeting WWOX gene. Int J Cancer 134: 811-821, 2014.

96. Xu Q, Sun Q, Zhang J, Yu J, Chen W and Zhang Z: Downregulation of miR-153 contributes to epithelial-mesenchymal transition and tumor metastasis in human epithelial cancer. Carcinogenesis 34: 539-549, 2013.

97. Baba O, Hasegawa S, Nagai H, Uchida F, Yamatoji M, Kanno NI, Yamagata K, Sakai S, Yanagawa T and Bukawa H: MicroRNA-155-5p is associated with oral squamous cell carcinoma metastasis and poor prognosis. J Oral Pathol Med 45: 248-255, 2016

98. Yang CC, Hung PS, Wang PW, Liu CJ, Chu TH, Cheng HW and Lin SC: miR-181 as a putative biomarker for lymph-node metastasis of oral squamous cell carcinoma. J Oral Pathol Med 40: 397-404, 2011.

99. Obayashi M, Yoshida M, Tsunematsu T, Ogawa I, Sasahira T, Kuniyasu H, Imoto I, Abiko Y, Xu D, Fukunaga S, et al: microRNA-203 suppresses invasion and epithelial-mesenchymal transition induction via targeting NUAK1 in head and neck cancer. Oncotarget 7: 8223-8239, 2016.

100. Chang KW, Liu CJ, Chu TH, Cheng HW, Hung PS, Hu WY and Lin SC: Association between high miR-211 microRNA expression and the poor prognosis of oral carcinoma. J Dent Res 87 1063-1068, 2008.

101. Liu X, Yu J, Jiang L, Wang A, Shi F, Ye H and Zhou X: MicroRNA-222 regulates cell invasion by targeting matrix metalloproteinase 1 (MMP1) and manganese superoxide dismutase 2 (SOD2) in tongue squamous cell carcinoma cell lines. Cancer Genomics Proteomics 6: 131-139, 2009.

102. Sun Q, Zhang J, Cao W, Wang X, Xu Q, Yan M, Wu X and Chen W: Dysregulated miR-363 affects head and neck cancer invasion and metastasis by targeting podoplanin. Int $\mathrm{J}$ Biochem Cell Biol 45: 513-520, 2013.

103. Huang WC, Chan SH, Jang TH, Chang JW, Ko YC, Yen TC, Chiang SL, Chiang WF, Shieh TY, Liao CT, et al: miRNA-491-5p and GIT1 serve as modulators and biomarkers for oral squamous cell carcinoma invasion and metastasis. Cancer Res 74: 751-764, 2014.

104. Liao L, Wang J, Ouyang S, Zhang P, Wang J and Zhang M: Expression and clinical significance of microRNA-1246 in human oral squamous cell carcinoma. Med Sci Monit 21: 776-781, 2015.

105. Manikandan M, Deva Magendhra Rao AK, Arunkumar G, Manickavasagam M, Rajkumar KS, Rajaraman R and Munirajan AK: Oral squamous cell carcinoma: microRNA expression profiling and integrative analyses for elucidation of tumourigenesis mechanism. Mol Cancer 15: 28, 2016.

106. Bhatlekar S, Fields JZ and Boman BM: HOX genes and their role in the development of human cancers. J Mol Med (Berl) 92 811-823, 2014

107. Marcinkiewicz KM and Gudas LJ: Altered epigenetic regulation of homeobox genes in human oral squamous cell carcinoma cells. Exp Cell Res 320: 128-143, 2014

108. Chen C, Zhang Y, Zhang L, Weakley SM and Yao Q: MicroRNA-196: Critical roles and clinical applications in development and cancer. J Cell Mol Med 15: 14-23, 2011.

109. Liu Y, Zhang Y, Wu H, Li Y, Zhang Y, Liu M, Li X and Tang H: miR-10a suppresses colorectal cancer metastasis by modulating the epithelial-to-mesenchymal transition and anoikis. Cell Death Dis 8: e2739, 2017.

110. Chen W, Tang Z, Sun Y, Zhang Y, Wang X, Shen Z, Liu F and Qin X: miRNA expression profile in primary gastric cancers and paired lymph node metastases indicates that miR-10a plays a role in metastasis from primary gastric cancer to lymph nodes. Exp Ther Med 3: 351-356, 2012

111. Harris T, Jimenez L, Kawachi N, Fan JB, Chen J, Belbin T, Ramnauth A, Loudig O, Keller CE, Smith R, et al: Low-leve expression of miR-375 correlates with poor outcome and metastasis while altering the invasive properties of head and neck squamous cell carcinomas. Am J Pathol 180: 917-928, 2012

112. Veit JA, Scheckenbach K, Schuler PJ, Laban S, Wiggenhauser PS, Thierauf J, Klussmann JP and Hoffmann TK: MicroRNA expression in differentially metastasizing tumors of the head and neck: Adenoid cystic versus squamous cell carcinoma. Anticancer Res 35: 1271-1277, 2015.
113. Min A, Zhu C, Peng S, Rajthala S, Costea DE and Sapkota D: MicroRNAs as important players and biomarkers in oral carcinogenesis. Biomed Res Int 2015: 186904, 2015.

114. Zahran F, Ghalwash D, Shaker O, Al-Johani K and Scully C: Salivary microRNAs in oral cancer. Oral Dis 21: 739-747, 2015.

115. Johnson JJ, Miller DL, Jiang R, et al: Protease-activated Receptor-2 (PAR-2)-mediated Nf- $\kappa \mathrm{B}$ activation suppresses inflammation-associated tumor Suppressor MicroRNAs in oral squamous cell carcinoma. J Biol Chem 291: 6936-6945, 2016.

116. Mascolo M, Siano M, Ilardi G, Russo D, Merolla F, De Rosa G and Staibano S: Epigenetic disregulation in oral cancer. Int J Mol Sci 13: 2331-2353, 2012

117. Hayashi M, Wu G, Roh JL, et al: Correlation of gene methylation in surgical margin imprints with locoregional recurrence in head and neck squamous cell carcinoma. Cancer 121: 1957-1965, 2015

118. Asli NS and Kessel M: Spatiotemporally restricted regulation of generic motor neuron programs by miR-196-mediated repression of Hoxb8. Dev Biol 344: 857-868, 2010.

119. Dasen JS: Long noncoding RNAs in development: solidifying the Lncs to Hox gene regulation. Cell Rep 5: 1-2, 2013.

120. Ma L: Role of miR-10b in breast cancer metastasis. Breast Cancer Res 12: 210, 2010.

121. Wu Y, Zhang L, Zhang L, Wang Y, Li H, Ren X, Wei F, Yu W, Liu T, Wang X, et al: Long non-coding RNA HOTAIR promotes tumor cell invasion and metastasis by recruiting EZH2 and repressing E-cadherin in oral squamous cell carcinoma. Int J Oncol 46: 2586-2594, 2015.

122. Adami GR, Tang JL and Markiewicz MR: Improving accuracy of RNA-based diagnosis and prognosis of oral cancer by using noninvasive methods. Oral Oncol 69: 62-67, 2017.

123. He Q, Chen Z, Cabay RJ, et al: microRNA-21 and microRNA-375 from oral cytology as biomarkers for oral tongue cancer detection. Oral Oncol 57: 15-20, 2016.

124. Koch FP, Kämmerer PW, Kämmerer P, Al-Nawas B and Brieger J: Influence of class M1 glutathione S-transferase (GST Mu) polymorphism on GST M1 gene expression level and tumor size in oral squamous cell carcinoma. Oral Oncol 46: 128-133, 2010.

125. Serrao NR, Reid SM and Wilson CC: Establishing detection thresholds for environmental DNA using receiver operator characteristic (ROC) curves. Conservation Genet Resour: 1-8, 2017.

126. MordhorstLB, Sorbe B and Ahlin C: A study of serum biomarkers associated with relapse of cervical cancer. Anticancer Res 32: 4913-4922, 2012

127. Hosmer DW Jr, Lemeshow S and Sturdivant RX (eds): Applied Logistic Regression. 3rd edition. John Wiley \& Sons, Hoboken, NJ, pp173-pp182, 2013.

128. Braoudaki M, Lambrou GI, Giannikou K, et al: miR-15a and miR-24-1 as putative prognostic microRNA signatures for pediatric pilocytic astrocytomas and ependymomas. Tumour Biol 37 9887-9897, 2016

129. Braoudaki M,Lambrou GI,PapadodimaSA,StefanakiK,ProdromouN and Kanavakis E: MicroRNA expression profiles in pediatric dysembryoplastic neuroepithelial tumors. Med Oncol 33: 5, 2016.

130. Hunt EA, Broyles D, Head T and Deo SK: MicroRNA detection Current technology and research strategies. Annu Rev Anal Chem (Palo Alto Calif) 8: 217-237, 2015.

131. Doleshal M, Magotra AA, Choudhury B, Cannon BD, Labourier E and Szafranska AE: Evaluation and validation of total RNA extraction methods for microRNA expression analyses in formalin-fixed, paraffin-embedded tissues. J Mol Diagn 10: 203-211, 2008.

132. Dai L, Wang Y, Chen L, Zheng J, Li J and Wu X: MiR-221, a potential prognostic biomarker for recurrence in papillary thyroid cancer. World J Surg Oncol 15: 11, 2017.

133. Li J, Smyth P, Flavin R, Cahill S, Denning K, Aherne S, Guenther SM, O'Leary JJ and Sheils O: Comparison of miRNA expression patterns using total RNA extracted from matched samples of formalin-fixed paraffin-embedded (FFPE) cells and snap frozen cells. BMC Biotechnol 7: 36, 2007.

134. Manikandan M, Deva Magendhra Rao AK, et al: Down regulation of miR-34a and miR-143 may indirectly inhibit p53 in oral squamous cell carcinoma: A pilot study. Asian Pac J Cancer Prev 16: 7619-7625, 2015.

135. Moratin J, Hartmann S, Brands R, et al: Evaluation of miRNA-expression and clinical tumour parameters in oral squamous cell carcinoma (OSCC). J Craniomaxillofac Surg 44: $876-881,2016$

This work is licensed under a Creative Commons Attribution-NonCommercial-NoDerivatives 4.0 International (CC BY-NC-ND 4.0) License. 